\title{
Applicability of RELAP5-3D for Thermal-Hydraulic Analyses of a Sodium-Cooled Actinide Burner Test Reactor
}

C. B. Davis

July 2006

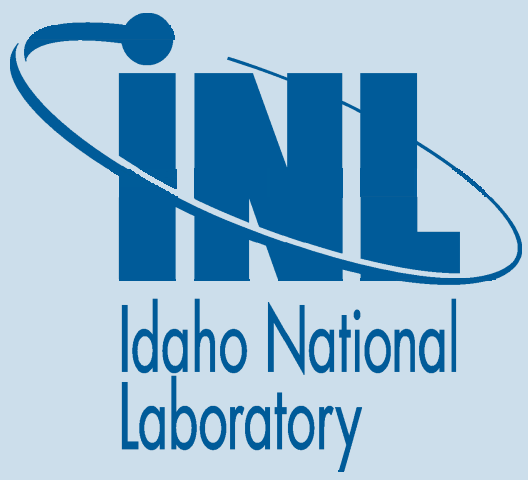

The INL is a U.S. Department of Energy National Laboratory operated by Battelle Energy Alliance 



\title{
Applicability of RELAP5-3D for Thermal-Hydraulic Analyses of a Sodium-Cooled Actinide Burner Test Reactor
}

\author{
C. B. Davis \\ July 2006 \\ Idaho National Laboratory \\ Idaho Falls, Idaho 83415 \\ Prepared for the \\ U.S. Department of Energy \\ Assistant Secretary for Nuclear Energy \\ Under DOE Idaho Operations Office \\ Contract DE-AC07-05ID14517
}




\section{SUMMARY}

The Actinide Burner Test Reactor (ABTR) is envisioned as a sodium-cooled, fast reactor that will burn the actinides generated in light water reactors to reduce nuclear waste and ease proliferation concerns. Thermal-hydraulic computer codes will have to be developed, verified, and validated to support the conceptual and final designs of the ABTR. The RELAP5-3D computer code is being considered as the thermal-hydraulic system code to support the development of the ABTR.

An evaluation was performed to determine the applicability of RELAP5-3D for the analysis of a sodiumcooled fast reactor. The applicability evaluation consisted of several steps, including identifying the important transients and phenomena expected in the ABTR, identifying the models and correlations that affect the code's calculation of the important phenomena, and evaluating the applicability of the important models and correlations for calculating the important phenomena expected in the ABTR. The applicability evaluation identified code improvements and additional models needed to better simulate the ABTR. The accuracy of the sodium properties used by the code was also evaluated.

The applicability evaluation generally showed that the existing models were adequate or that relatively minor changes were required to improve the code's representation of the important phenomena. However, new models are required to represent electromagnetic pumps and axial conduction in the fluid. Long-term improvements will also be needed to better represent the decay heat associated with the actinides burned by the reactor, the effects of thermal expansion of various core components on reactivity feedback, and the Reynolds-number dependence on the form loss coefficient for orifices. The evaluation of fluid properties indicated that the specific heat capacity of the liquid phase should be changed to better represent the values expected during normal operation and during transients. 


\section{CONTENTS}

SUMMARY

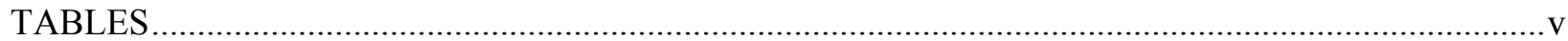

FIGURES …

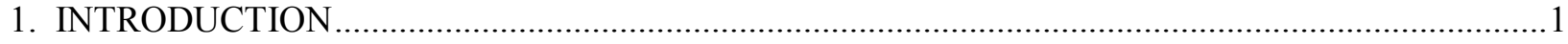

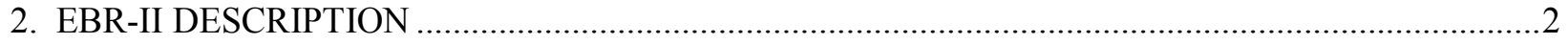

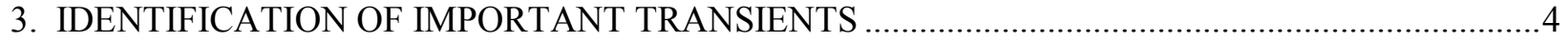

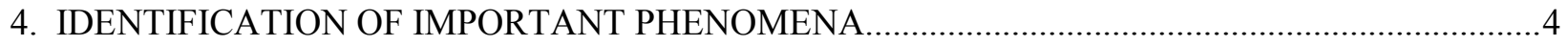

5. IDENTIFICATION AND APPLICABILITY EVALUATION OF IMPORTANT MODELS ...............5

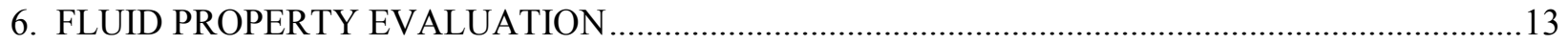

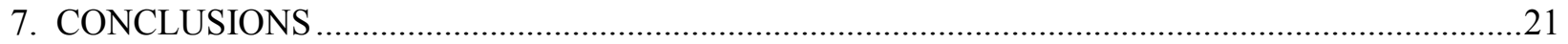

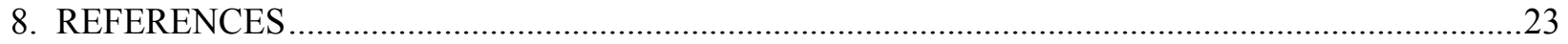

TABLES

1. Summary of fluid property comparisons

\section{FIGURES}

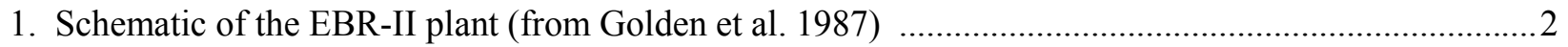

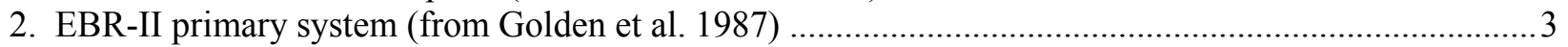

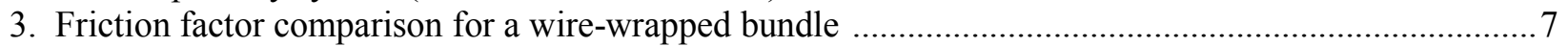

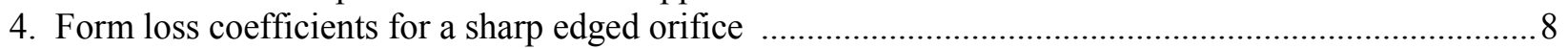

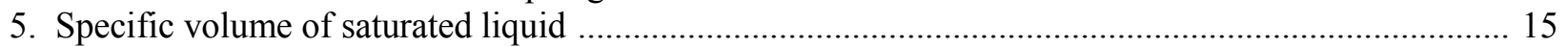

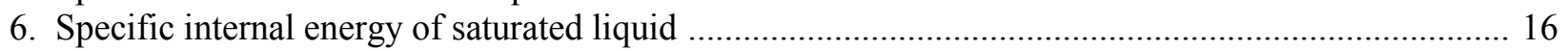

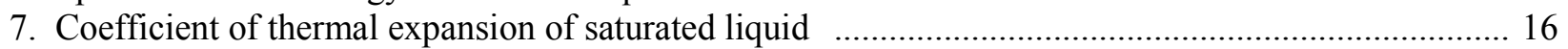

8. Coefficient of isothermal compressibility of saturated liquid .................................................... 16

9. Specific heat capacity at constant pressure of saturated liquid ........................................................ 17

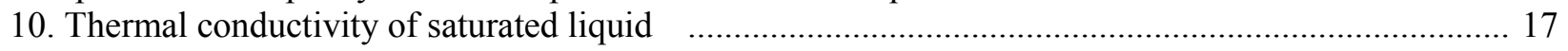

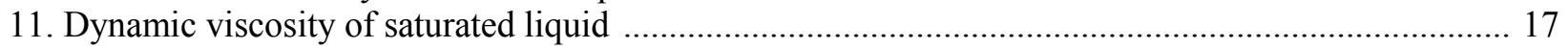

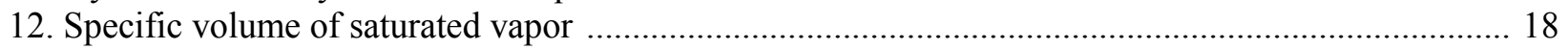

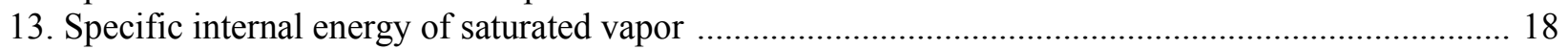

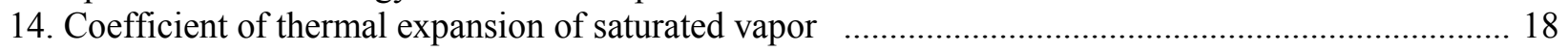

15. Coefficient of isothermal compressibility of saturated vapor .......................................................... 19

16. Specific heat capacity at constant pressure of saturated vapor ........................................................ 19

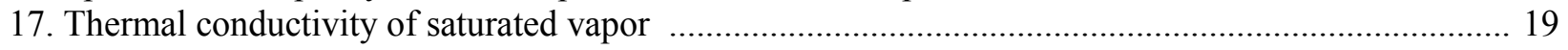

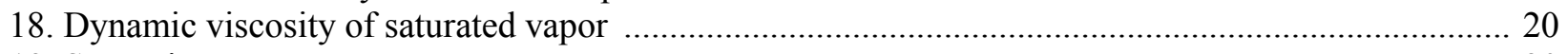

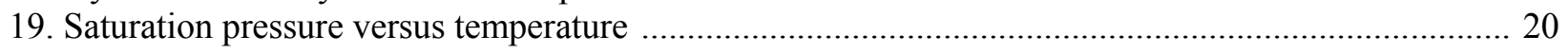

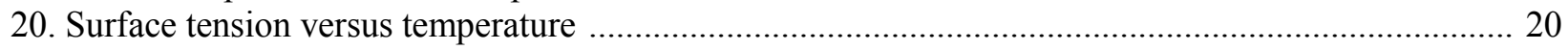




\section{INTRODUCTION}

The Actinide Burner Test Reactor (ABTR) is envisioned as a sodium-cooled, fast reactor that will burn the actinides generated in light water reactors to reduce nuclear waste and ease proliferation concerns. Thermal-hydraulic computer codes will have to be developed, verified, and validated to support the conceptual and final designs of the ABTR. The RELAP5-3D computer program (RELAP5-3D Development Team 2005) is being considered as the thermal-hydraulic system code to support the development of the ABTR. RELAP5-3D has been primarily developed to simulate thermal-hydraulic transients in reactor systems that use light water as the working fluid. However, the code has a generalized capability to simulate a wide range of working fluids other than light water, including various liquid metals, such as sodium and the eutectics of lead-bismuth and sodium-potassium, various gases, including helium, carbon dioxide, nitrogen, and hydrogen, liquid salts, and other miscellaneous fluids, such as ammonia.

The RELAP5 series of codes has been extensively used and validated for thermal-hydraulic analysis of reactors cooled by light water. However, the code has not been validated as thoroughly for non-aqueous working fluids in general and sodium in particular. Consequently, an evaluation was performed to determine the applicability of the code for the analysis of a sodium-cooled fast reactor. The applicability evaluation consisted of several steps. The first step was to identify the important phenomena expected in the ABTR during normal operation and important transients. This step was complicated by the fact that the conceptual design of the ABTR has not yet been developed and thus the important transients relative to safety can not be currently identified. The ABTR will probably be similar to the Experimental Breeder Reactor-II (EBR-II) although the total power may be higher. Thus, EBR-II was evaluated to help identify important transients and phenomena. The second step in the applicability evaluation was to identify the important models and correlations that affect the code's calculation of the important phenomena. The third step was to evaluate the applicability of the important models and correlations for calculating the important phenomena expected in the ABTR. Part of this evaluation was to identify code improvements and additional models needed to simulate the ABTR. The final step was to evaluate the accuracy of the thermodynamic and transport properties used by the code for sodium.

The ABTR design is expected to preclude the occurrence of boiling in the sodium except for the most severe of accidents. The RELAP5-3D code contains a generalized capability to represent two-phase flow in each working fluid. However, the validations performed to date for the two-phase models have been primarily for light water. Although the two-phase models could, in principle, be validated for sodium, the amount of work required would probably greatly outweigh the benefits derived. Consequently, this evaluation concentrated on single-phase phenomena. Other codes that have already been validated, such as SASSYS (Dunn et al. 1985), should probably be utilized to simulate the severe accidents in the ABTR that would result in two-phase conditions rather than validate RELAP5-3D for two-phase applications with sodium.

A computational fluid dynamics (CFD) code will eventually have to be validated to support the thermalhydraulic development of the ABTR. This document evaluates the applicability of the RELAP5-3D code for the systems analysis requirements of the ABTR. Development needs and an applicability evaluation for a CFD code will be considered later.

Section 2 of this report provides a brief description of EBR-II. Sections 3 and 4 identify the transients and phenomena that are expected to be important in the safety evaluations of the ABTR. Section 5 identifies the important RELAP5-3D models and evaluates their applicability for analyses of the ABTR. 
The adequacy of the code's sodium fluid properties is evaluated in Section 6. Conclusions and references are provided in Sections 7 and 8, respectively.

\section{EBR-II DESCRIPTION}

The EBR-II plant is described by Golden et al. (1987), Lehto el al. (1987), and Berkan et al. (1990). EBR-II contained primary and secondary coolant systems that utilized liquid sodium as the working fluid and a conventional steam system as illustrated in Figures 1 and 2. The primary coolant system was submerged within a large pool of sodium within a tank. Full power operation was at $62.5 \mathrm{MWt}$ with inlet and outlet temperatures of 371 and $473{ }^{\circ} \mathrm{C}$.

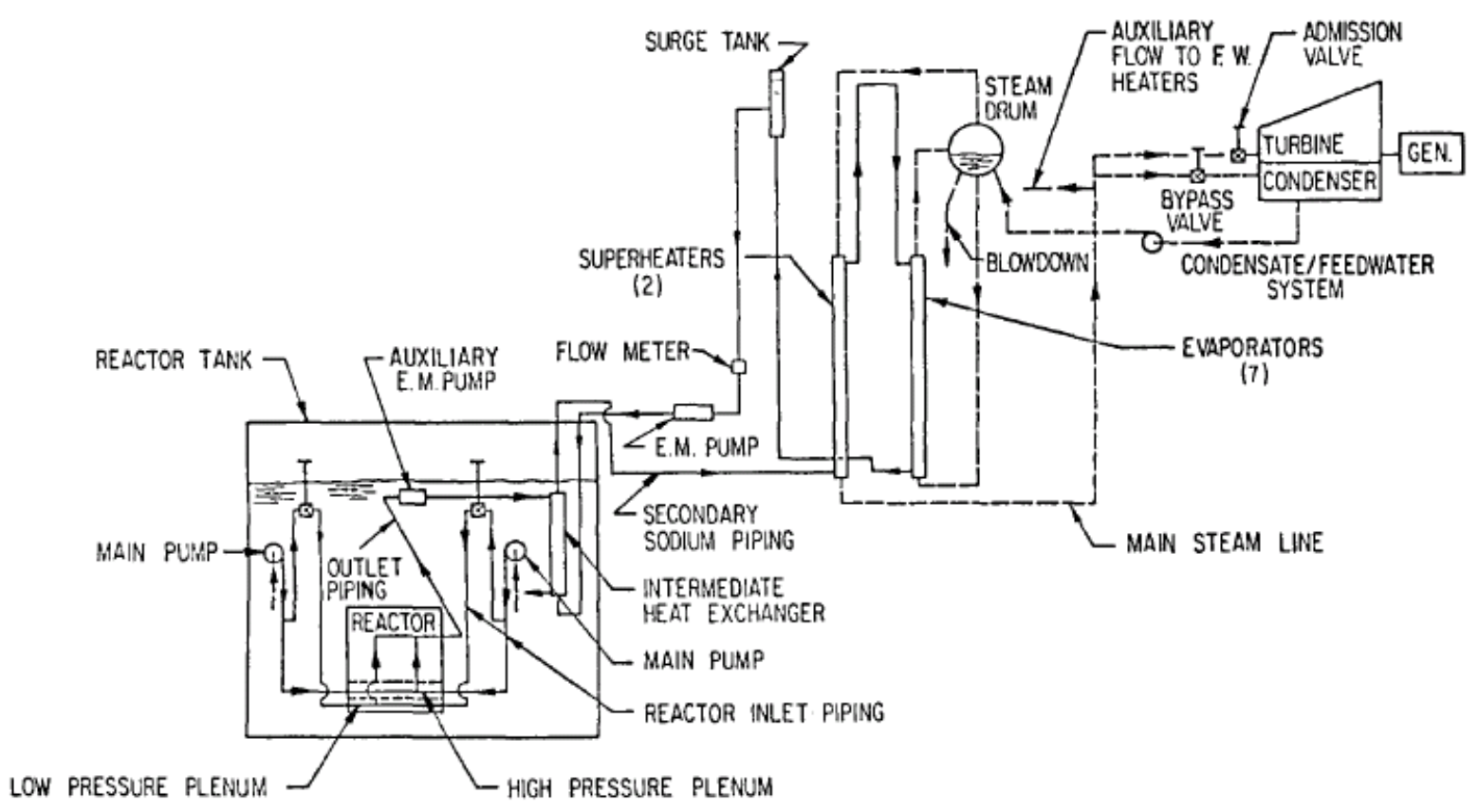

Figure 1. Schematic of the EBR-II plant (from Golden et al. 1987). 


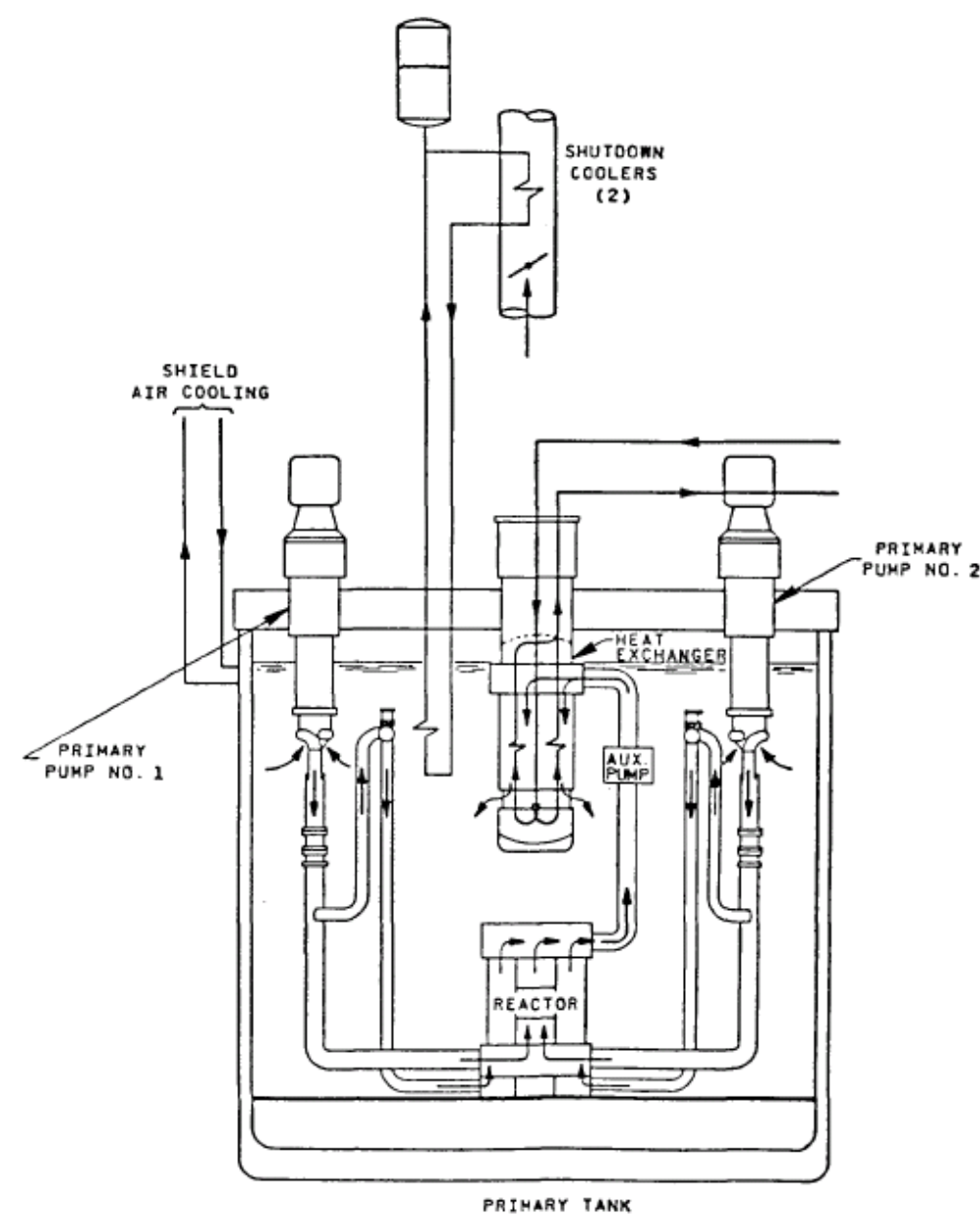

Figure 2. EBR-II primary system (from Golden et al. 1987).

The active core was approximately $0.34 \mathrm{~m}$ tall and $0.5 \mathrm{~m}$ in diameter. The reactor contained hexagonal driver subassemblies that were surrounded by reflector and blanket subassemblies. The driver subassemblies contained up to 91 fuel pins that were $0.0033 \mathrm{~m}$ in diameter and $0.61 \mathrm{~m}$ tall. The fuel pins contained a relatively long upper plenum to accommodate the accumulation of fission gases. The driver fuel pins contained a metallic uranium alloy fuel that was enriched to $66 \%{ }^{235} \mathrm{U}$. Sodium was used to thermally bond the fuel and the 316 stainless steel cladding. The fuel pins were spirally wrapped with wire to maintain the spacing between rods. The reflector subassemblies contained stainless steel. The blanket assemblies contained depleted uranium slugs enclosed in stainless steel tubes. Orifices were used to control the flow to the various subassemblies.

Flow through the primary coolant system was generated by two centrifugal primary pumps and an auxiliary electromagnetic pump. The primary coolant pumps drew fluid from the pool and forced it into the reactor inlet piping. The flow then passed through the reactor into an outlet plenum, into the reactor outlet piping, through the auxiliary electromagnetic pump, and into an intermediate heat exchanger (IHX). The primary sodium leaving the IHX was discharged into the reactor pool.

The secondary coolant system utilized sodium as a working fluid and transported heat from the IHX to the tertiary steam system. Flow through the secondary coolant system was driven by an electromagnetic pump. The steam system contained seven evaporators, a steam drum, two superheaters, a turbine and 
condenser, and connecting piping. The heat exchangers utilized a double-wall design to assure that the sodium and water remained separated.

A passive system was used to provide long-term decay heat removal. The decay heat was removed from the reactor pool via a shutdown cooling system that utilized natural circulation of $\mathrm{NaK}$ and transported heat to the atmosphere through air-cooled shutdown coolers. Louvers on the air side of the shutdown cooler were closed during normal operation, but opened automatically on high reactor inlet temperature (Feldman et al. 1987). The shutdown cooling system was able to remove about $0.6 \%$ of the rated core power.

\section{IDENTIFICATION OF IMPORTANT TRANSIENTS}

The Shutdown Heat Removal Test Program (Golden et al. 1987) was conducted in EBR-II to demonstrate passive reactor shutdown following a loss of forced circulation and a loss of heat sink. Although experiments were also performed with scram, the experiments of primary interest were conducted without scram to demonstrate the inherent safety features of the design. Transients initiated by a loss of forced convection and loss of heat sink are also expected to be important transients in the ABTR. The ABTR will likely be required to have safety margins at least as large as those demonstrated in EBR-II. Thus, the ABTR will likely have to survive transients initiated by loss of forced convection and loss of heat sink without reactor scram.

The figure of merit for evaluating the safety of the EBR-II was the peak temperature at the interface between the fuel and the cladding (Lehto et al. 1987). The temperature of the inner surface of the cladding was limited to $715^{\circ} \mathrm{C}$ during normal operation and during anticipated transients. For unlikely transients, the maximum temperature was required to be less than $815^{\circ} \mathrm{C}$, with less than $60 \mathrm{~s}$ of operation above $715^{\circ} \mathrm{C}$ allowed.

The station blackout with reactor scram will likely be the limiting event for the design of the shutdown cooling system in the ABTR and thus will be an important transient. The station blackout will cause a loss of forced flow in the primary and secondary coolant systems and will result in a simultaneous loss of heat sink and forced convection through the core. A passive shutdown cooling system, such as the Reactor Vessel Auxiliary Cooling System (RVACS), will likely be required to keep the reactor adequately cooled for an indefinite period of time. Passive systems like RVACS have been an integral part of the safety design of other proposed reactors cooled by liquid metals (Hejzlar and Davis 2004 and Boardman et al. 2000) and will likely be required for the ABTR. Note that the shutdown cooling system in the EBR-II, which performed a function analogous to RVACS, was not important during the loss of heat sink transient in the Shutdown Removal Heat Test Program because the secondary flow rate could not be stopped completely and the IHX continued to remove a small amount of power during the tests.

\section{IDENTIFICATION OF IMPORTANT PHENOMENA}

The cladding temperature during a transient initiated by a loss of forced convection without scram is primarily determined by the flow rate, the inlet fluid temperature, the heat transfer between the fuel rod and the fluid, and the reactor power. The phenomena and parameters that affect these important phenomena are discussed below.

The flow rate through the subassembly is governed by the frictional characteristics of the subassembly and the coastdown characteristics of the primary coolant pumps. The frictional characteristics of the subassembly are expected to be dominated by those of the inlet orifice and the wire-wrapped rod bundle. 
Because of the relatively short ( $\sim 100 \mathrm{~s})$ period between the onset of the transient and the occurrence of the peak cladding temperature, the inlet fluid temperature may be considered to be nearly constant, at least up until the time of the occurrence of the temperature peak. During longer transients, mixing and thermal stratification within the reactor tank can significantly affect the inlet fluid temperature and thus the cladding temperature (Mohr et al. 1987). The performance of the secondary coolant system, the power conversion unit, and the passive decay heat removal system all affect the cladding temperature during longer transients.

The heat transfer from the fuel rod and coolant is governed by the heat conduction within the fuel rod and the convective heat transfer at the outer surface of the fuel rod to the coolant. Because of the high thermal conductivity of sodium, axial conduction within the fluid and radial conduction between adjacent subchannels within a subassembly can be significant.

The reactor power during a transient without scram is governed by reactivity feedback effects. In addition to common feedback mechanisms, such as due to changes in coolant density and Doppler, EBRII had additional feedback mechanisms caused by the thermal expansion of various components, including the fuel, upper and lower reflectors, control rod driveline, and upper grid plate. Radial expansion of the core and thermal bowing were also important (Lehto et al. 1987).

The reactor power is also affected by the decay power, particularly at low fission power levels. The decay heat characteristics of the driver subassemblies, which are expected to be enriched with U-235 in the ABTR, and the blanket assemblies, which are expected to be depleted of U-235, are expected to differ considerably.

The important phenomena in the loss of heat sink transient are included in those described previously for the loss of forced convection with the exception that the passive heat removal by the RVACS or equivalent system will be important for the ABTR. The RVACS or equivalent system is responsible for transferring the core decay heat to the ultimate heat sink. Natural circulation within the core and reactor tank will also be important phenomena for the station blackout transient.

\section{IDENTIFICATION AND APPLICABILITY EVALUATION OF IMPORTANT MODELS}

This section identifies the important code models that affect the calculation of the important phenomena identified in the previous section. This section also presents an evaluation of the applicability of the existing models for the analysis of the ABTR. Improvements in RELAP5-3D needed to model the ABTR are identified where necessary.

\section{Frictional Characteristics}

The frictional characteristics of the wire-wrapped rod bundles and the orifice at the bottom of the rod bundles are expected to be important in the analysis of the ABTR. The important RELAP5-3D models to represent these frictional characteristics are the wall and form friction models.

Cheng and Todreas (1986) give correlations for the frictional pressure drop of wire-wrapped rod bundles. Empirical correlations were provided for the transitions between laminar and turbulent regimes that depended on the Reynolds number $(\mathrm{Re})$ of the bundle and the pitch-to-diameter $(\mathrm{P} / \mathrm{D})$ ratio of the rods. These empirical correlations are

$\operatorname{Re}<\operatorname{Re}_{\mathrm{L}}$ for the laminar regime where $\operatorname{Re}_{\mathrm{L}}=10^{1.7(\mathrm{P} / \mathrm{D}-1)+\log _{10} 300}$ and 
$\operatorname{Re}>\operatorname{Re}_{\mathrm{T}}$ for the turbulent regime where $\operatorname{Re}_{\mathrm{T}}=10^{0.7(\mathrm{P} / \mathrm{D}-1)+4}$ and

$\operatorname{Re}_{\mathrm{L}}<\operatorname{Re}<\operatorname{Re}_{\mathrm{T}}$ for transition regime.

The Darcy friction factors, $\mathrm{f}$, for the rod bundle are defined as

$\mathrm{f}_{\mathrm{L}}=\mathrm{C}_{\mathrm{fL}} / \mathrm{Re}$ for the laminar regime

$\mathrm{f}_{\mathrm{T}}=\mathrm{C}_{\mathrm{fT}} / \mathrm{Re}^{0.18}$ for the turbulent regime and

$\mathrm{f}=\mathrm{f}_{\mathrm{L}}(1-\psi)^{1 / 3}+\mathrm{f}_{\mathrm{T}} \psi^{1 / 3}$ for the transition regime, where

$\mathrm{C}_{\mathrm{fL}}=\left\{-974.6+1612(\mathrm{P} / \mathrm{D})-598.5(\mathrm{P} / \mathrm{D})^{2}\right\}(\mathrm{H} / \mathrm{D})^{0.06-0.085(\mathrm{P} / \mathrm{D})}$

$\mathrm{C}_{\mathrm{fT}}=\left\{0.8063-0.9022 \log _{10}(\mathrm{H} / \mathrm{D})+0.3526\left(\log _{10}(\mathrm{H} / \mathrm{D})\right)^{2}\right\}(\mathrm{P} / \mathrm{D})^{9.7}(\mathrm{H} / \mathrm{D})^{1.78-2.0(\mathrm{P} / \mathrm{D})}$

$\psi=\log _{10}\left(\operatorname{Re} / \operatorname{Re}_{\mathrm{L}}\right) / \log _{10}\left(\operatorname{Re}_{\mathrm{T}} / \operatorname{Re}_{\mathrm{L}}\right)$,

and $\mathrm{H}$ is the axial lead (height of one revolution) of the wire wrap. The correlations are applicable for

$1.025 \leq \mathrm{P} / \mathrm{D} \leq 1.42,8.0 \leq \mathrm{H} / \mathrm{D} \leq 50.0$, and $50 \leq \mathrm{Re} \leq 10^{6}$.

The friction factor correlations predict most of the data within $10 \%$ except at the extreme values of P/D and H/D. Cheng and Todreas (1986) also present equations that quantify the effect of the wire wrap on the bundle flow area and hydraulic diameter. The effect of the wire wrap is included in the calculation of the Reynolds number.

The RELAP5-3D wall friction model contains correlations for the friction factor in laminar, turbulent, and transition regions. The laminar friction factor model is based on the exact solution for fully developed flow and constant fluid properties

$\mathrm{f}_{\mathrm{L}}=\frac{64}{\operatorname{Re} \phi} \quad$,

where $\phi$ is a shape factor that allows the user to account for geometries other than a circular tube. Setting

$\phi=\frac{64}{\mathrm{C}_{\mathrm{fL}}}$ allows the code to exactly match the friction factor for laminar flow.

RELAP5-3D calculates the turbulent friction factor using the Zigrang-Sylvester (1985) approximation to the Colebrook-White (1939) correlation

$$
\frac{1}{\sqrt{f_{\mathrm{T}}}}=-2 \log _{10}\left(\frac{\varepsilon / \mathrm{D}_{\text {hy }}}{3.7}+\frac{2.51}{\operatorname{Re}}\left(1.14-2 \log _{10}\left(\frac{\varepsilon}{\mathrm{D}_{\text {hy }}}+\frac{21.25}{\mathrm{Re}^{0.9}}\right)\right)\right),
$$


where $\varepsilon$ is the surface roughness and $\mathrm{D}_{\text {hy }}$ is the hydraulic diameter. In addition to the default model described in Equation 11, the code also allows an optional, alternate turbulent wall friction model in which the friction factor is calculated from

$$
\mathrm{f}_{\mathrm{T}}=\mathrm{A}+\mathrm{BRe}^{-\mathrm{C}}
$$

where $\mathrm{A}, \mathrm{B}$, and $\mathrm{C}$ are constants that the user may specify for each control volume. Setting $\mathrm{A}=0, \mathrm{~B}=$ $\mathrm{C}_{\mathrm{fT}}$, and $\mathrm{C}=0.18$ allows the optional model to match Equation 5 .

RELAP5-3D assumes that the transition between laminar and turbulent flow occurs between Reynolds numbers of 2200 and 3000 and obtains the friction factor by interpolating between the laminar value at a Reynolds number of $2200, \mathrm{f}_{\mathrm{L}, 2200}$, and the turbulent value at a Reynolds number of $3000, \mathrm{f}_{\mathrm{T}, 3000}$, to obtain

$$
\mathrm{f}=\left(3.75-\frac{8250}{\operatorname{Re}}\right)\left(\mathrm{f}_{\mathrm{T}, 3000}-\mathrm{f}_{\mathrm{L}, 2200}\right)+\mathrm{f}_{\mathrm{L}, 2200}
$$

The RELAP5-3D model defined by Equations 10, 12, and 13 was compared with the correlation of Cheng and Todreas (1986) for $\mathrm{P} / \mathrm{D}=1.3$ and $\mathrm{H} / \mathrm{D}=30$ as shown in Figure 3. For these parameters, the transition region identified in Equation 3 is between Reynolds numbers of 980 and 16,000, which differs

considerably from the region assumed by the code. The friction factor from the RELAP5-3D model was less than that from the correlation, with a maximum error of $40 \%$ at a Reynolds number of 2200 . As expected, the friction factor calculated by the code was identical to that from the correlation at Reynolds numbers below 980 and above 16,000. These results indicate that the code's wall friction model needs to be improved to adequately represent wire-wrapped rod bundles in the transition region between laminar and turbulent flow.

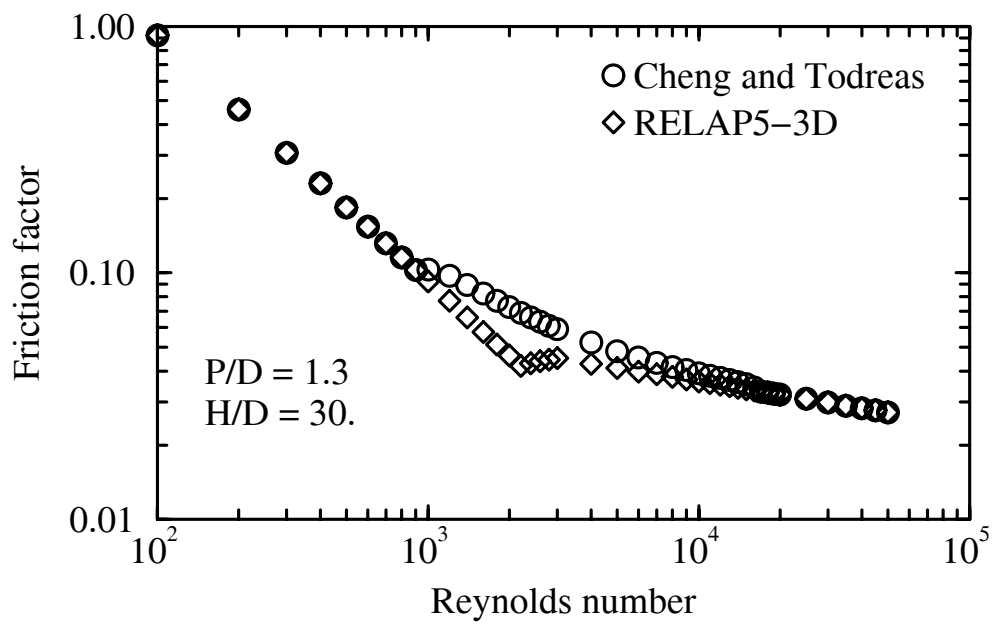

Figure 3. Friction factor comparison for a wire-wrapped bundle.

The code's default wall friction correlations (Equations 10,11, and 13) should be adequate to represent the other components in the ABTR, including pipes and heat exchangers.

The frictional characteristics of the orifice in a subassembly are expected to be important in modeling the ABTR. The RELAP5-3D user normally represents the frictional characteristics of an orifice with a constant form loss coefficient. However, the code allows the user to optionally input the form loss coefficient with a Reynolds number dependence 


$$
\mathrm{k}=\mathrm{A}+\mathrm{BRe}^{-\mathrm{C}}
$$

where $\mathrm{A}, \mathrm{B}$, and $\mathrm{C}$ are input constants that must be $\geq 0$.

Idelchik (1994) presents correlations for the form loss coefficient of a sharp-edged orifice as a function of Reynolds number. The results from Idelchik were fit to the functional form given by Equation 14 for a case where the area of the orifice was $20 \%$ of that of the upstream pipe and the areas of the upstream and downstream pipes were the same. Figure 4 shows that the functional form used by RELAP5-3D was in reasonable agreement with the values from Idelchik at higher Reynolds numbers. The fitted values were within $10 \%$ of the values from Idelchik for Reynolds numbers between 200 and 1.E6. However, the fitted value of the $\mathrm{B}$ constant was negative, which would require a minor change to the present coding. The fitted results were about 30\% too low at a Reynolds number of 40, and more importantly, exhibited the wrong trend at Reynolds numbers below 200. These results indicate that a more general equation than that given in Equation 14 is required to accurately represent the frictional characteristics of a sharp-edged orifice if a very wide range of Reynolds numbers needs to be simulated.

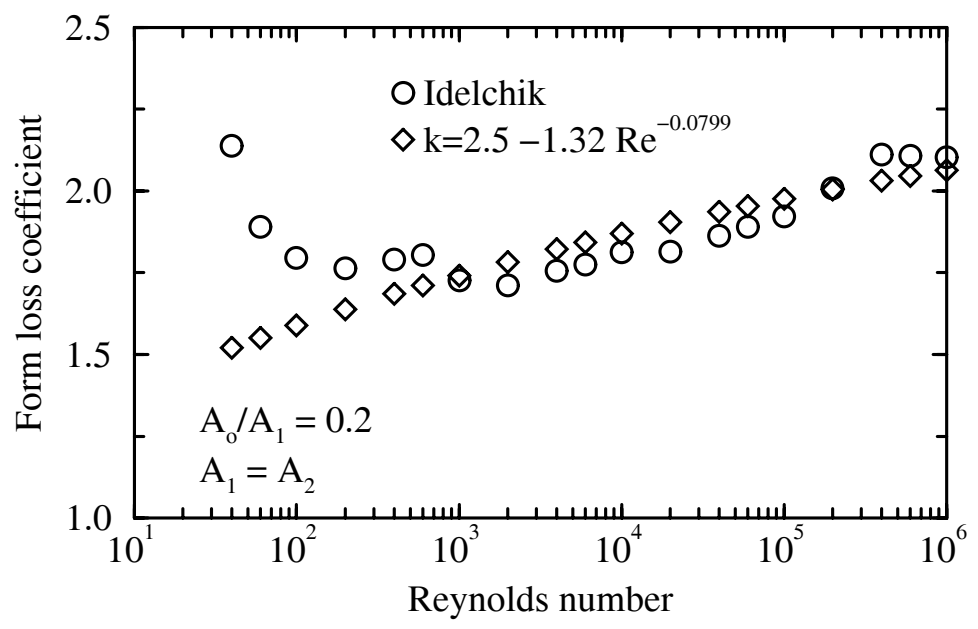

Figure 4. Form loss coefficients for a sharp-edged orifice.

\section{Pumps}

EBR-II utilized both centrifugal and electromagnetic pumps. RELAP5-3D has a centrifugal pump model that represents pump performance based on homologous curves. The model has been applied to a wide variety of pumps and should be adequate to characterize the behavior of the centrifugal pumps in the ABTR. RELAP5-3D does not have an electromagnetic pump model, but one will probably be needed to simulate the ABTR. Proposals to implement an electromagnetic pump model in RELAP5-3D have been made previously, but were never funded. The implementation of the previously proposed model should be adequate for the analysis of the ABTR.

\section{Thermal Stratification}

Mixing and thermal stratification within the reactor tank can significantly affect the inlet fluid temperature and thus the cladding temperature during long transients (Mohr et al. 1987). The mixing processes within the reactor tank are governed by multi-dimensional natural circulation phenomena and turbulent mixing. Although RELAP5-3D has three-dimensional momentum equations, the equations do not include the second order viscous terms that determine turbulent mixing. Consequently, the code is not expected to perform an accurate, mechanistic calculation of the mixing processes. In previous 
analyses, the effects of mixing and thermal stratification were bounded through nodalization studies, where perfect mixing was simulated by using a large single volume and other nodalization schemes were used to simulate limited mixing. Similar bounding analyses are also likely to be possible for the ABTR.

RELAP5-3D has been coupled (Schultz et al. 2005) to Fluent, a CFD code. Since Fluent has the capability to represent thermal stratification in a tank with a free surface, it should be able to perform mechanistic mixing calculations for the ABTR. The coupling of RELAP5-3D and Fluent allows integrated, mechanistic calculations in which RELAP5-3D performs a computationally efficient simulation of the majority of the reactor systems including the reactor core, most of the primary coolant system, the secondary coolant system, power conversion unit, and decay heat removal systems and Fluent is used to perform detailed analyses of the reactor tank. Fluent can also be run by itself to help determine a RELAP5-3D nodalization that reasonably represents the stratification phenomena in a given transient. In addition to Fluent, other computational fluid dynamics codes are being developed that are expected to support the development of the ABTR.

No changes are deemed necessary in RELAP5-3D to represent thermal stratification in the reactor tank because of its capability for nodalization studies while running in the stand alone mode and the combined capabilities of the coupled RELAP5-3D and Fluent codes.

\section{Secondary and Other Systems}

The performance of the secondary coolant system, the power conversion unit, and the decay heat removal systems will affect the core inlet fluid temperature during long transients.

The most important components in the secondary coolant system are the pump and the IHX. As mentioned previously, RELAP5-3D needs an electromagnetic pump model if that option is used in the design of the ABTR. RELAP5-3D has been used to model a variety of heat exchangers and the existing models should be adequate to represent the IHX in the ABTR.

RELAP5-3D was originally developed to simulate thermal-hydraulic systems that utilized light water as the working fluid. Although RELAP5-3D has generally been used to simulate the primary coolant system, the code has also been successfully used to simulate the power conversion unit of light water reactors (see Liang et al. 2004 for example). Thus, the code should be able to adequately represent the power conversion unit of the ABTR.

RELAP5-3D has also been used to simulate air-cooled RVACS decay heat removal systems for a fast reactor cooled by a lead alloy (Hejzlar and Davis 2004) and a thermal reactor cooled by liquid salt (Davis and Hawkes 2006). RELAP5-3D also contains NaK as a working fluid. Thus, the code should be able to adequately model the passive decay heat removal system in the ABTR.

\section{Heat Transfer}

The maximum cladding temperature is affected by heat conduction within the fuel, the heat transfer across the gap, heat conduction within the cladding, and the heat transfer from the surface of the cladding to the coolant. The existing heat conduction models in RELAP5-3D should adequately represent the heat conduction across the fuel and the cladding in the ABTR. RELAP5-3D has simple models to calculate gap conductance and geometrical changes in light water reactor fuel rods. These models are expected to be applicable to the ABTR if it uses oxide fuel, but will not be applicable if it uses metallic fuel with a sodium bond. In either case, it is expected that a detailed fuel rod performance code will be used to determine appropriate parameters for use in RELAP5-3D system calculations so that the geometry of the 
fuel rod during normal operation is correctly represented. Thus, no changes are required in RELAP5-3D to model the performance of the ABTR fuel rods.

The heat transfer from the surface of the fuel rod cladding to the coolant is governed by the heat transfer correlations used by RELAP5-3D. The default correlation for single-phase heat transfer to liquid metals in RELAP5-3D is

$$
\mathrm{Nu}=5.0+0.025 \mathrm{Pe}^{0.8} \quad \text { (constant wall temperature) }
$$

where $\mathrm{Nu}$ is the Nusselt number, $\mathrm{Pe}$ is the Peclet number, which is the Reynolds number times the Prandtl number. Equation 15 is based on a semitheoretical treatment (Bird et al. 1960) and is appropriate for fully developed flow in liquid metals with constant fluid properties. Bird et al. also present a corresponding equation for constant heat flux

$$
\mathrm{Nu}=7.0+0.025 \mathrm{Pe}^{0.8} \text { (constant heat flux) }
$$

Equation 16 is probably more applicable for the ABTR core than Equation 15 because fast reactors tend to have relatively flat power profiles and thus the constant heat flux assumption is expected to be more accurate than the constant wall temperature assumption. Based on the normal operating conditions in the EBR-II core, the heat transfer coefficient from Equation 16 is about 30\% greater than that from Equation 15. It is recommended that RELAP5-3D be changed to utilize the constant heat flux form rather than the constant wall temperature form.

RELAP5-3D also has an optional heat transfer correlation that was developed by Westinghouse for rod bundles with liquid metals. The Westinghouse correlation (Todreas and Kazimi 1990) is

$$
\mathrm{Nu}=4.0+0.33(\mathrm{P} / \mathrm{D})^{3.8}(\mathrm{Pe} / 100)^{0.86}+0.16(\mathrm{P} / \mathrm{D})^{5.0}
$$

and applies for $1.1 \leq \mathrm{P} / \mathrm{D} \leq 1.4$ and $10 \leq \mathrm{Pe} \leq 5000$. Todreas and Kazimi showed that the Westinghouse correlation agreed well with experimental data at $\mathrm{P} / \mathrm{D}=1.15$, but underestimated the Nusselt number at $\mathrm{P} / \mathrm{D}=1.30$. Based on those results, the Westinghouse correlation would be expected to underestimate the Nusselt number in the EBR-II core at normal operating conditions by about $30 \%$. Todreas and Kazimi showed that the correlation of Borishanskii et al. (1969)

$$
\begin{aligned}
& \mathrm{Nu}=24.15 \log \left\{-8.12+12.76(\mathrm{P} / \mathrm{D})-3.65(\mathrm{P} / \mathrm{D})^{2}\right\} \text { for } 1.1<\mathrm{P} / \mathrm{D}<1.5 \text { and } \mathrm{Pe} \leq 200 \text { and } \\
& \mathrm{Nu}=24.15 \log \left\{-8.12+12.76(\mathrm{P} / \mathrm{D})-3.65(\mathrm{P} / \mathrm{D})^{2}\right\}+0.0174\left(1-\mathrm{e}^{(6-6 \mathrm{P} / \mathrm{D})}\right)\{\mathrm{Pe}-200\}^{0.9} \text { for } 200 \leq \mathrm{Pe} \leq 2000
\end{aligned}
$$

more accurately reflected the experimental data, particularly at larger values of P/D. Consequently, it is recommended that the bundle correlation in RELAP5-3D be changed from the Westinghouse correlation to the correlation of Borishanskii et al. Note that the implementation of Equations 16 and 18 requires only minor changes to the coding.

Equations 15 and 16 are applicable for fully developed flow. The thermal entry length depends on the Prandtl number and is longer for fluids with low Prandtl numbers, such as liquid metals, than for water. The Prandtl number in the EBR-II core during normal operation was about 0.005 whereas the value for liquid water is generally greater than 1.0. Based on the results presented by Kays and Crawford (1980), the enhancement in the local heat transfer coefficient due to the thermal entry effect in the EBR-II core was probably about $10 \%$ at a length-to-diameter ratio of 10 . Since the length in the EBR-II core was more than 100 times the hydraulic diameter and the maximum cladding temperature occurs near the outlet of the core, the effects of the thermal entry length on the heat transfer can be reasonably neglected. 


\section{Conduction in the Fluid}

RELAP5-3D neglects axial conduction in the working fluid because the thermal conductivity of water is relatively low. However, the thermal conductivity of sodium is about 100 times greater than that of water. Thus, the effects of axial conduction were evaluated to determine their potential impact on the ABTR. According to Kays and Crawford (1980), axial conduction can be an important factor in liquid metal heat transfer. They present a simple rule of thumb that states that axial conduction may affect the heat transfer if the Peclet number is less than 100. The average Peclet number in the core during normal operation of EBR-II was about 100. Because the flow decreased by about a factor of 20 during loss-ofprimary flow tests in EBR-II (Mohr et al. 1987), the Peclet number could be reduced to about 5. Thus, the effects of axial conduction could be significant in the analysis of the ABTR, particularly during transients with reduced flow. Thus, the capability to model axial conduction in the fluid should be added to RELAP5-3D. Proposals to add the axial conduction capability to the code have been made previously, but were not funded. The implementation of the previously proposed model should be adequate for the analysis of the ABTR.

RELAP5-3D also neglects the effects of radial conduction in the working fluid such as would occur between two adjacent subchannels in a subassembly. A scoping evaluation of the effect of radial conduction between subchannels in EBR-II during a loss-of-flow transient (Mohr et al. 1987) indicated that the radial conduction could be significant, particularly at lower flows. Thus, radial conduction in the fluid would have to be added to the code to model subchannel effects. Turbulent mixing effects would also have to be added to RELAP5-3D to accurately represent subchannel effects. Subchannel effects are usually calculated with subchannel or CFD codes rather than with a system code. Since RELAP5-3D probably will not be used to model subchannel effects in the ABTR, radial conduction and subchannel mixing models are not required at this time.

\section{Reactivity Feedback Effects}

The reactor power during a transient without scram is governed by reactivity feedback effects. As described previously, EBR-II had reactivity feedback mechanisms that depended on the thermal expansion of various components. Accurate simulation of these effects requires coupled thermal and mechanical calculations to determine the effect of temperature on the geometry of the core components and feedback coefficients that account for the effects of the geometry on the reactivity. An alternative approach is to use feedback coefficients that account for the various expansions based on simplified (external) mechanical calculations and changes in core inlet, outlet, or average fluid temperatures. This simplified approach was used previously in analyses of lead-alloy cooled fast reactors (Hejzlar and Davis 2004). Another approach would be to use the RELAP5-3D control system to perform simplified thermal expansion calculations based on the calculated temperatures of the appropriate fluid and structure regions. This approach would allow the reactivity feedback effects to be coupled to the code's thermal calculations and the simplified mechanical calculations from the control system, but would require extra work on the part of the user. The most accurate approach, and the one that would require the least amount of work on the part of the user, would be to add mechanical models to the code that calculate the effects of thermal expansion on reactivity. However, this approach seems premature since the mechanical design of the ABTR has yet to be defined. Thus, no changes to the code are judged to be needed at this time to represent the effects of reactivity feedback in the ABTR. However, once the design matures it would be appropriate to add mechanical models to RELAP5-3D or link it to a structural analysis code that represents the effects of thermal expansion on the core geometry.

RELAP5-3D has a multi-dimensional nodal reactor kinetics capability based on the NESTLE code (Turinsky et al. 1994) for transients where the spatial distribution of the neutron flux changes with time. 
NESTLE applies the neutron diffusion equations with up to four groups of neutrons for Cartesian and hexagonal cores. However, more than four energy groups would probably be required to adequately model a fast reactor such as the ABTR. Thus, additional development would likely be required to support the capability to simulate transients in which the power shape varies with time. This capability is not required to simulate the important transients identified in Section 3, but might be required to simulate other transients, such as those with an asymmetric control rod response.

\section{Decay Heat}

RELAP5-3D allows the decay heat to be calculated based on several American Nuclear Society (ANS) standards, including the proposed 1973 standard, the 1979 standard, and the 1994 standard. The ANS standards are based on the decay heat associated with the thermal fission of ${ }^{235} U(1973,1979$, and 1994), the fast fission of ${ }^{238} \mathrm{U}$ (1979 and 1994), the thermal fission of ${ }^{239} \mathrm{Pu}(1979$ and 1994), and the thermal fission of ${ }^{241} \mathrm{Pu}$ (1994). The 1979 and 1994 standards also provide models for the decay heat produced by

${ }^{239} \mathrm{U}$ and ${ }^{239} \mathrm{~Np}$ actinides. The default values for the various exponentials used to calculate the fission product and actinide decay are specified in the standards. However, the code allows the user to specify the fission product yield fraction and decay constant for up to 50 fission product groups and two actinides. The code also allows the user to calculate decay power from a general table or a control variable.

The composition of the fuel for the ABTR has not yet been specified, but Hejzlar and Davis (2004) identified the fuel composition for an actinide burning reactor cooled by a lead alloy. The fuel included uranium, thorium, plutonium $\left({ }^{238} \mathrm{Pu},{ }^{239} \mathrm{Pu},{ }^{240} \mathrm{Pu},{ }^{241} \mathrm{Pu}\right.$, and $\left.{ }^{242} \mathrm{Pu}\right)$, and minor actinides $\left({ }^{237} \mathrm{~Np},{ }^{241} \mathrm{Am}\right.$, ${ }^{242} \mathrm{Am},{ }^{243} \mathrm{Am}$, and $\left.{ }^{244} \mathrm{Cm}\right)$. The decay heat characteristics from such fuel are likely to differ considerably from those of a light water reactor for which the ANS standards were developed because of the different isotopes involved. Consequently, it is expected that the RELAP5-3D decay heat model will have to be revised to account for the different isotopes present in the ABTR. Explicit models will probably be required to mechanistically account for the decay heat associated with the various actinides. However, decay heat calculations that are available from other sources, such as from ORIGEN (Croff 1980), can be easily modeled in RELAP5-3D using a general table.

The decay heat characteristics of the driver and blanket subassemblies in the EBR-II differed because the driver assemblies were enriched with ${ }^{235} \mathrm{U}$ while the blanket assemblies were depleted of ${ }^{235} \mathrm{U}$. The decay power calculation in RELAP5-3D depends on the fraction and history of fission power generated in each fissile isotope. The fraction of fission power generated by each isotope in the EBR-II core varied considerably between the driver and blanket subassemblies. The existing RELAP5-3D model can mechanistically represent the fission power fractions in either a driver assembly or a blanket subassembly, but could not mechanistically represent the fractions in both regions at the same time. This problem could also be complicated by variations in the enrichments and fission fractions between regular and control driver subassemblies. This limitation of the code is not considered to be too serious because the decay heat model could be based on the characteristics of an average driver assembly while the decay heat characteristics of the blanket subassemblies could be simulated through a general table or control variable based on the results of a separate RELAP5-3D calculation.

\section{Natural Circulation}

Natural circulation within the core and reactor tank was identified as important in the loss of forced circulation and station blackout transients. Natural circulation is governed by the balance between the frictional and hydrostatic forces. The hydrostatic forces are governed by the fluid temperature distribution, which depends on the core power, the heat sinks, and the flow rates. The code's models of the frictional forces, fission power, and decay heat were described previously. 
RELAP5-3D has been used to calculate natural circulation in a wide variety of applications. The existing models should be adequate to predict natural circulation in the ABTR.

\section{FLUID PROPERTY EVALUATION}

The coolant temperature in most sodium-cooled fast reactors varies between 600 and $840 \mathrm{~K}$ during normal operation. The average fluid temperature in EBR-II was $695 \mathrm{~K}$. The fluid temperature can increase during transients, but should remain less than the cladding safety limit, which was $988 \mathrm{~K}$ for anticipated transients and $1088 \mathrm{~K}$ for unlikely events in EBR-II (Lehto et al. 1987). The temperature can also decrease during transients, with the melting temperature of $371 \mathrm{~K}$ providing the lower bound. The principal range of interest for ABTR applications is expected to be between 600 and $1100 \mathrm{~K}$. The average fluid temperature during normal operation of the ABTR is expected to be near $700 \mathrm{~K}$.

RELAP5-3D utilizes various fluid properties, including the thermodynamic properties of specific volume, specific internal energy, coefficients of thermal expansion and isothermal compressibility, and specific heat capacity at constant pressure and the transport properties of thermal conductivity and dynamic viscosity. The code also utilizes surface tension and the saturation line. Thermodynamic and transport properties are required for both liquid and vapor phases because RELAP5-3D is a two-fluid code.

The code obtains sodium thermodynamic properties by interpolating from tables located in an auxiliary file called 'tpfna'. The tables are generated by an equation of state that is based on a soft sphere model (Young 1977). The soft sphere model assumes that the specific Helmholtz free energy is the sum of five different energy terms, including kinetic, static lattice potential, thermal lattice potential, attractive potential, and cohesive energy terms. Each term is expressed as a function of temperature and specific volume and includes constant multipliers. The multipliers vary from metal to metal and consist of three constants and five adjustable parameters. The constants include an fec Madelung constant, the number of atoms per kilogram of metal, and cohesive lattice energy. The adjustable parameters are calculated by means of curve fits. Correlations are used to determine the transport properties, surface tension, and saturation line.

Fink and Leibowitz (1995) of Argonne National Laboratory (ANL) provided thermodynamic and transport properties of saturated sodium liquid and vapor between the melting and critical temperatures $(371-2504 \mathrm{~K})$. They also estimated the uncertainty in various properties as a function of temperature. The ANL values were compared with those calculated by RELAP5-3D between temperatures of 371 and $2000 \mathrm{~K}$, which exceeds the $600-1100 \mathrm{~K}$ range of primary interest for the ABTR. Results are summarized in Table 1.

Table 1 presents the root-mean-square (rms) error for each parameter, the fractional deviation between the RELAP5-3D and ANL values, and the fractional estimated uncertainty at temperatures of 600, 1000, 1500 and $2000 \mathrm{~K}$. The table also provides an overall judgment of the adequacy of the properties calculated by RELAP5-3D compared to the values from ANL. A judgment of excellent was given when the calculation exhibits no deficiencies in modeling a given parameter and the calculated results, with few exceptions, lie within the specified or inferred uncertainty bands. A judgment of reasonable was given when the calculated results provides an overall acceptable prediction, with all major trends predicted correctly. The calculated results frequently lied outside, but near, the specified or inferred uncertainty bands. A judgment of minimal was given when the calculated results exhibited significant deficiencies in that some major trends were not predicted correctly or the calculated values lie considerably outside the specified uncertainty bands. A judgment of insufficient was given when the calculated results exhibited major deficiencies. 
Table 1. Summary of fluid property comparisons.

\begin{tabular}{|c|c|c|c|c|c|c|}
\hline Parameter & $\mathrm{n}^{\mathrm{a}}$ & $\mathrm{T}(\mathrm{K})$ & $|E|^{b}$ & Frac. unc. & rms error $^{\mathrm{c}}$ & Judgment \\
\hline $\begin{array}{l}\text { Liquid specific } \\
\text { volume }\end{array}$ & 18 & $\begin{array}{l}600 \\
1000 \\
1500 \\
2000 \\
\end{array}$ & $\begin{array}{l}0.0096 \\
0.0223 \\
0.0397 \\
0.0904 \\
\end{array}$ & $\begin{array}{l}0.003 \\
0.004 \\
0.027 \\
0.14 \\
\end{array}$ & 0.0399 & Reasonable \\
\hline $\begin{array}{l}\text { Liquid specific } \\
\text { internal energy }\end{array}$ & 18 & $\begin{array}{l}600 \\
1000 \\
1500 \\
2000 \\
\end{array}$ & $\begin{array}{l}0.0710 \\
0.0673 \\
0.0438 \\
0.0093\end{array}$ & $\begin{array}{l}0.01^{\mathrm{d}} \\
0.01^{\mathrm{d}} \\
0.014^{\mathrm{d}} \\
0.02^{\mathrm{d}}\end{array}$ & 0.0516 & Reasonable \\
\hline $\begin{array}{l}\text { Liquid coefficient of } \\
\text { thermal expansion }\end{array}$ & 18 & $\begin{array}{l}600 \\
1000 \\
1500 \\
2000 \\
\end{array}$ & $\begin{array}{l}0.147 \\
0.0902 \\
0.114 \\
0.294 \\
\end{array}$ & $\begin{array}{l}0.10 \\
0.10 \\
0.15 \\
0.45 \\
\end{array}$ & 0.162 & Reasonable \\
\hline $\begin{array}{l}\text { Liquid coefficient of } \\
\text { isothermal } \\
\text { compressibility }\end{array}$ & 18 & $\begin{array}{l}600 \\
1000 \\
1500 \\
2000\end{array}$ & $\begin{array}{l}0.0631 \\
0.0750 \\
0.121 \\
0.299\end{array}$ & $\begin{array}{l}0.08^{\mathrm{d}} \\
0.13^{\mathrm{d}} \\
0.34^{\mathrm{d}}\end{array}$ & 0.132 & Excellent \\
\hline $\begin{array}{l}\text { Liquid specific heat } \\
\text { capacity at constant } \\
\text { pressure }\end{array}$ & 18 & $\begin{array}{l}600 \\
1000 \\
1500 \\
2000\end{array}$ & $\begin{array}{l}0.0994 \\
0.0315 \\
0.0144 \\
0.184\end{array}$ & $\begin{array}{l}0.02 \\
0.02 \\
0.03 \\
0.20\end{array}$ & 0.0838 & Minimal \\
\hline $\begin{array}{l}\text { Liquid thermal } \\
\text { conductivity }\end{array}$ & 18 & $\begin{array}{l}600 \\
1000 \\
1500 \\
2000 \\
\end{array}$ & $\begin{array}{l}0.0246 \\
0.0550 \\
0.0365 \\
0.203 \\
\end{array}$ & $\begin{array}{l}0.05 \\
0.10 \\
0.15 \\
0.15 \\
\end{array}$ & 0.0692 & Excellent \\
\hline $\begin{array}{l}\text { Liquid dynamic } \\
\text { viscosity }\end{array}$ & 18 & $\begin{array}{l}600 \\
1000 \\
1500 \\
2000 \\
\end{array}$ & $\begin{array}{l}0.0085 \\
0.0084 \\
0.0308 \\
0.0497 \\
\end{array}$ & $\begin{array}{l}0.03 \\
0.04 \\
0.05 \\
0.10 \\
\end{array}$ & 0.0260 & Excellent \\
\hline $\begin{array}{l}\text { Vapor specific } \\
\text { volume }\end{array}$ & 18 & $\begin{array}{l}600 \\
1000 \\
1500 \\
2000 \\
\end{array}$ & $\begin{array}{l}0.0165 \\
0.0543 \\
0.0276 \\
0.0356 \\
\end{array}$ & $\begin{array}{l}0.06 \\
0.03 \\
0.08 \\
0.15 \\
\end{array}$ & 0.0696 & Reasonable \\
\hline $\begin{array}{l}\text { Vapor specific } \\
\text { internal energy }\end{array}$ & 18 & $\begin{array}{l}600 \\
1000 \\
1500 \\
2000 \\
\end{array}$ & $\begin{array}{l}0.0232 \\
0.0271 \\
0.0174 \\
0.0229 \\
\end{array}$ & $\begin{array}{l}0.01 \\
0.01 \\
0.02 \\
0.04 \\
\end{array}$ & 0.0221 & Reasonable \\
\hline $\begin{array}{l}\text { Vapor coefficient of } \\
\text { thermal expansion }\end{array}$ & 18 & $\begin{array}{l}600 \\
1000 \\
1500 \\
2000 \\
\end{array}$ & $\begin{array}{l}0.170 \\
0.325 \\
0.244 \\
0.0477\end{array}$ & $\begin{array}{l}0.15 \\
0.15 \\
0.15 \\
0.30\end{array}$ & 0.221 & Reasonable \\
\hline $\begin{array}{l}\text { Vapor coefficient of } \\
\text { isothermal } \\
\text { compressibility }\end{array}$ & 18 & $\begin{array}{l}600 \\
1000 \\
1500 \\
2000 \\
\end{array}$ & $\begin{array}{l}0.0262 \\
0.0413 \\
0.0294 \\
0.0238 \\
\end{array}$ & $\mathrm{NA}^{\mathrm{e}}$ & 0.0343 & Excellent \\
\hline $\begin{array}{l}\text { Vapor specific heat } \\
\text { capacity at constant } \\
\text { pressure }\end{array}$ & 17 & $\begin{array}{l}600 \\
1000 \\
1500 \\
2000 \\
\end{array}$ & $\begin{array}{l}0.497 \\
0.658 \\
0.547 \\
0.405 \\
\end{array}$ & $\begin{array}{l}0.20 \\
0.15 \\
0.15 \\
0.35 \\
\end{array}$ & 0.534 & Insufficient \\
\hline $\begin{array}{l}\text { Vapor thermal } \\
\text { conductivity }\end{array}$ & 5 & & & $\mathrm{NA}^{\mathrm{e}}$ & $0.0247^{f}$ & Excellent \\
\hline $\begin{array}{l}\text { Vapor dynamic } \\
\text { viscosity }\end{array}$ & & & & $\mathrm{NA}^{\mathrm{e}}$ & $0.0089^{f}$ & Excellent \\
\hline
\end{tabular}




\begin{tabular}{|c|c|c|c|c|c|c|}
\hline Saturation pressure & 18 & $\begin{array}{l}600 \\
1000 \\
1500 \\
2000 \\
\end{array}$ & $\begin{array}{l}0.0080 \\
0.0025 \\
0.0176 \\
0.0356\end{array}$ & $\begin{array}{l}0.06 \\
0.03 \\
0.03 \\
0.04\end{array}$ & 0.0237 & Excellent \\
\hline Surface tension & 18 & $\begin{array}{l}600 \\
1000 \\
1500 \\
2000\end{array}$ & $\begin{array}{l}0.0088 \\
0.0025 \\
0.0094 \\
0.0112\end{array}$ & $\begin{array}{l}0.11 \\
0.11 \\
0.11 \\
0.12\end{array}$ & 0.0341 & Excellent \\
\hline
\end{tabular}

a. Number of points, $n$, used to calculate the rms error.

b. Normalized error, $\mathrm{E}=(\mathrm{R}-\mathrm{A}) / \mathrm{A}$, where $\mathrm{R}$ is the value calculated by RELAP5-3D and $\mathrm{A}$ is the ANL value.

c. $\quad r m s=\sqrt{\frac{1}{n} \sum_{\mathrm{i}} \mathrm{E}_{\mathrm{i}}{ }^{2}}$

d. Estimated from data given by Fink and Leibowitz (1995).

e. Not available.

f. The calculated values for these parameters were compared with values given by Vargaftik (1975).

Results of the fluid property comparisons are shown in Figures 5 through 20. Figures 5 through 11 show comparisons of thermodynamic and transport properties for saturated sodium liquid, while Figures 12 through 18 show the corresponding comparisons for saturated sodium vapor. Figures 19 and 20 show the saturation pressure and the surface tension as a function of temperature.

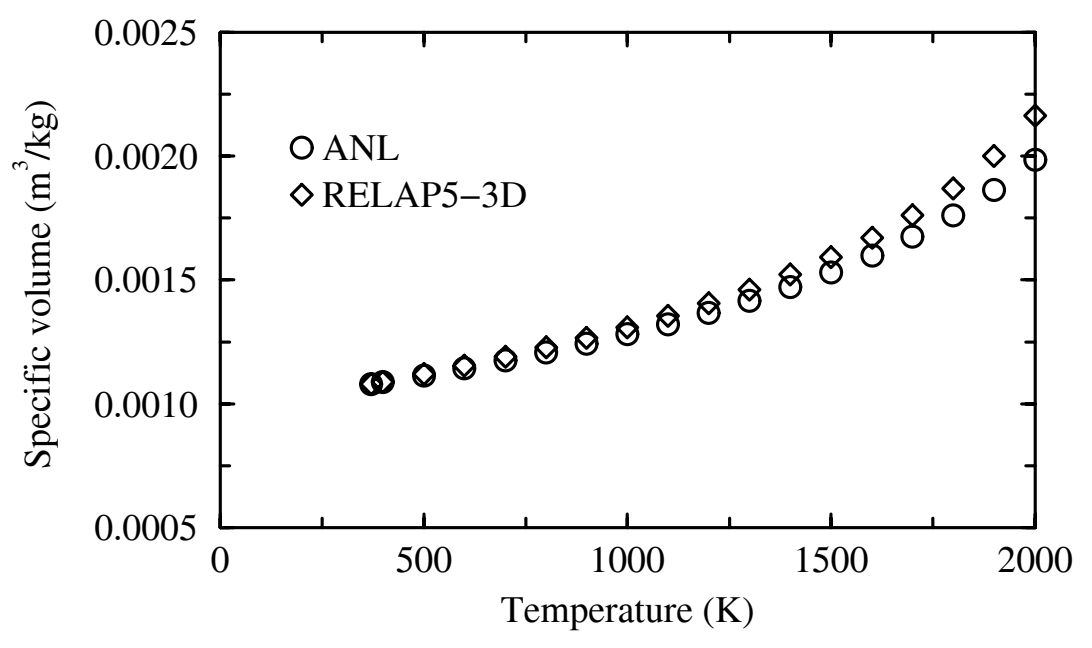

Figure 5. Specific volume of saturated liquid. 


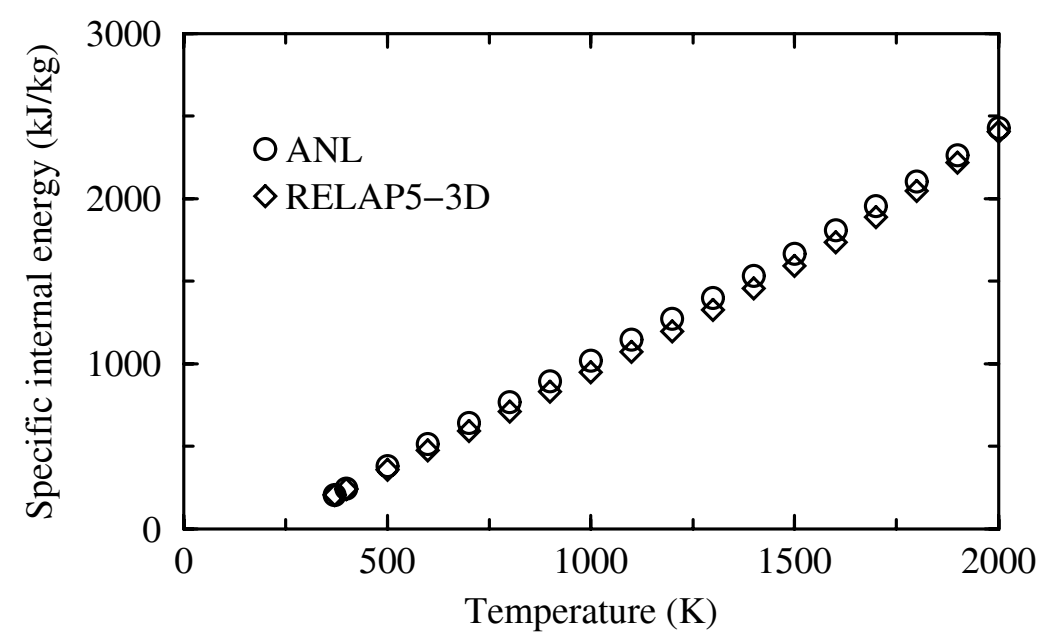

Figure 6. Specific internal energy of saturated liquid.

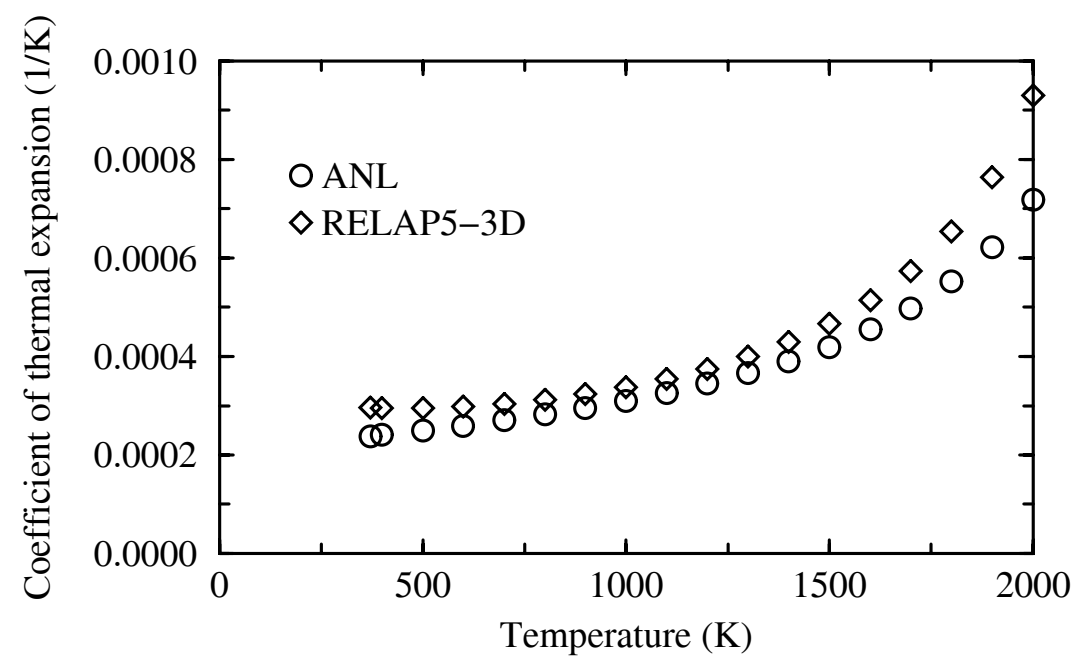

Figure 7. Coefficient of thermal expansion of saturated liquid.

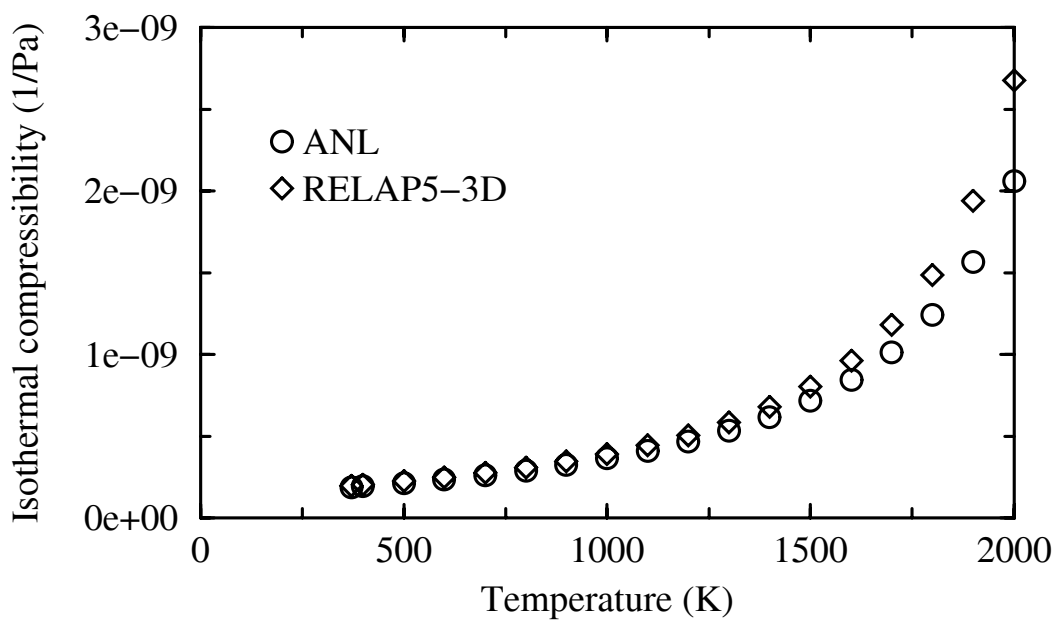

Figure 8. Coefficient of isothermal compressibility of saturated liquid. 


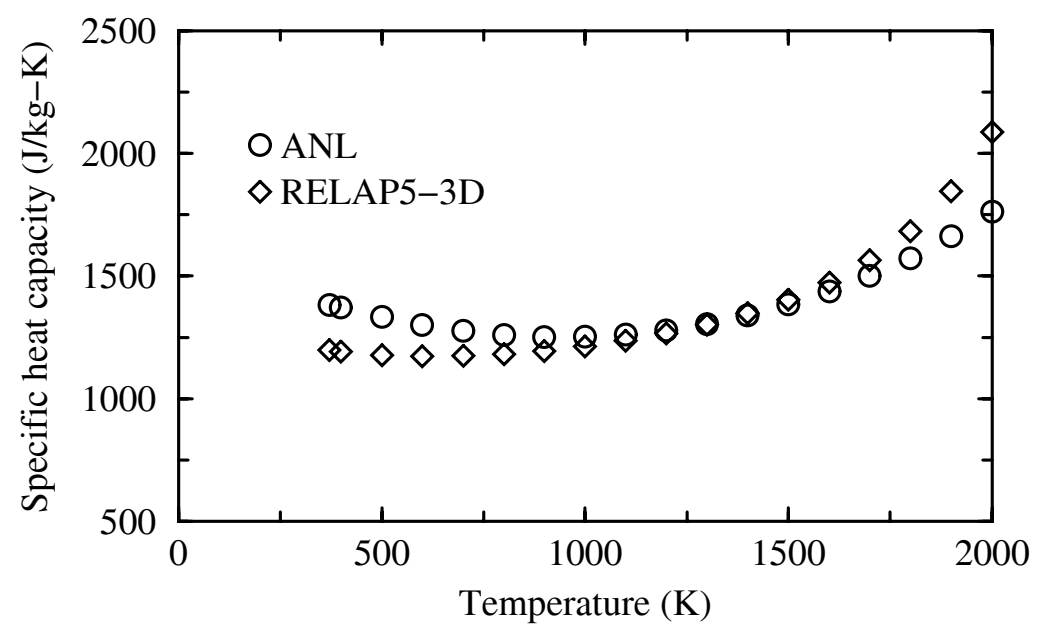

Figure 9. Specific heat capacity at constant pressure of saturated liquid.

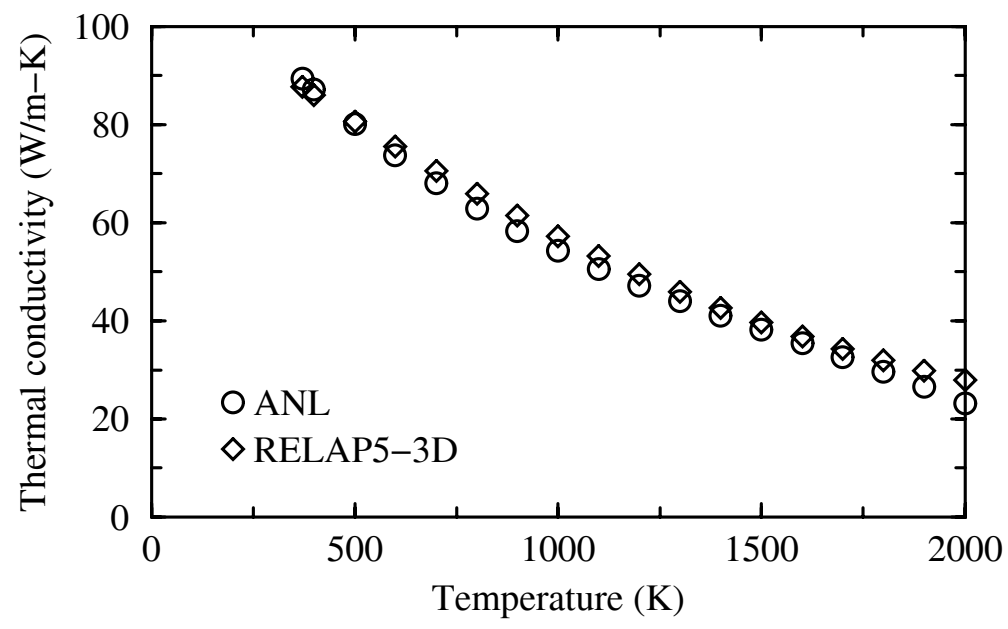

Figure 10. Thermal conductivity of saturated liquid.

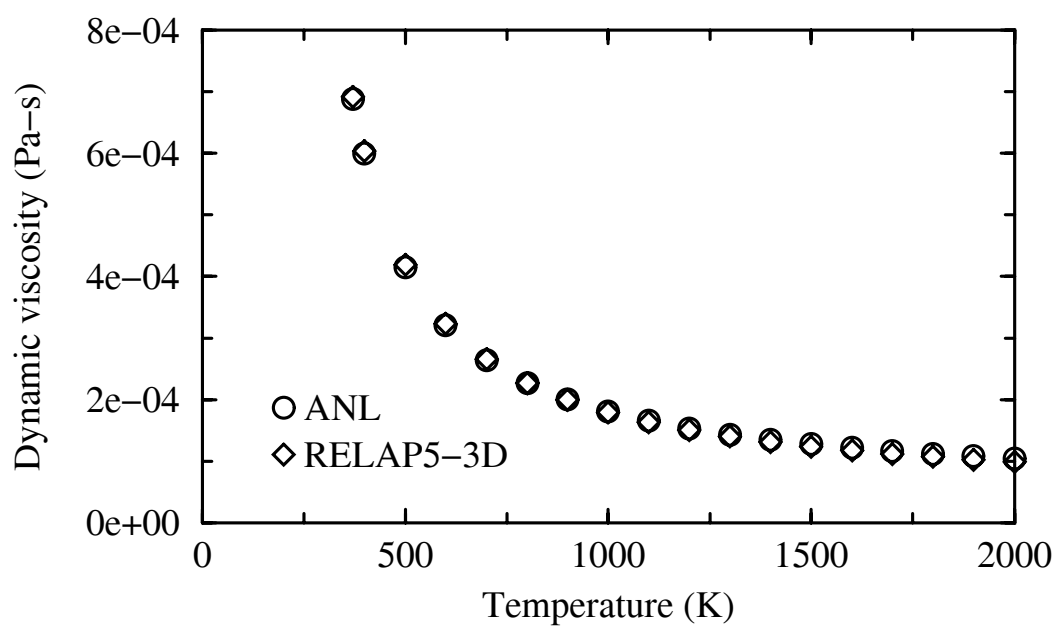

Figure 11. Dynamic viscosity of saturated liquid. 


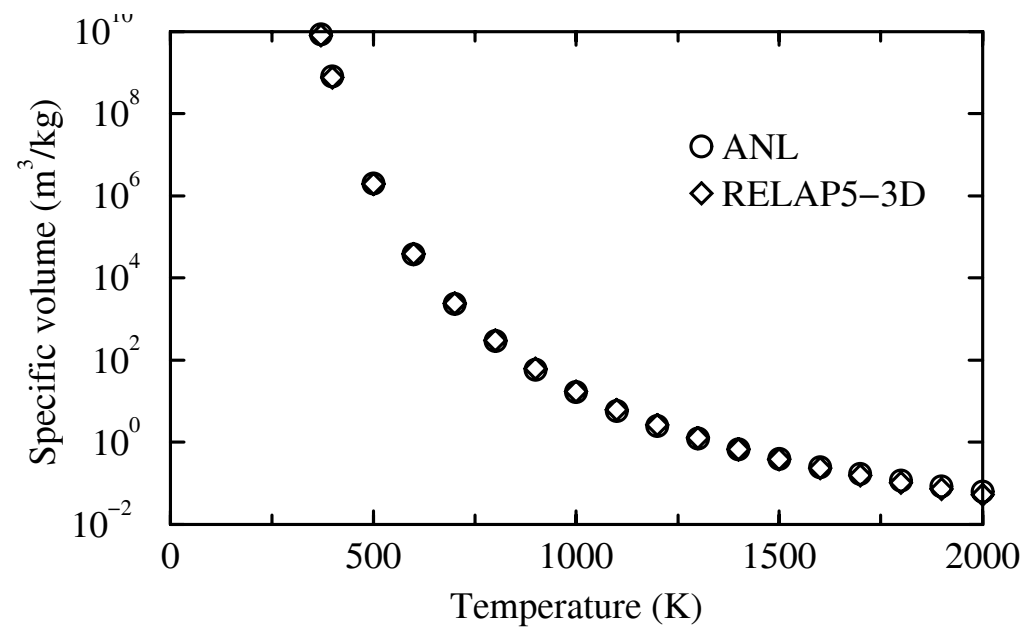

Figure 12. Specific volume of saturated vapor.

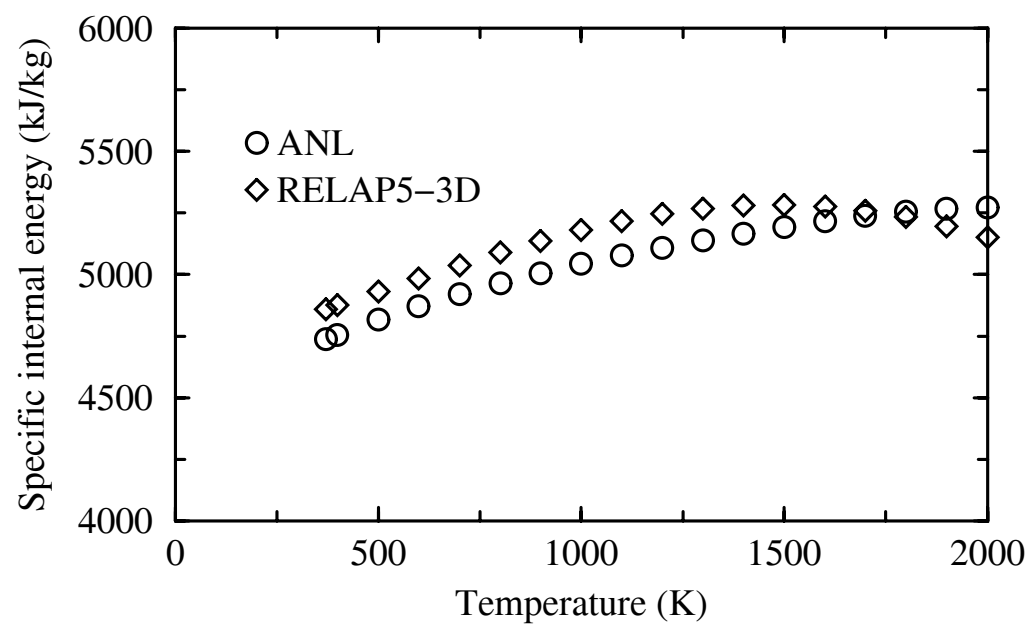

Figure 13. Specific internal energy of saturated vapor.

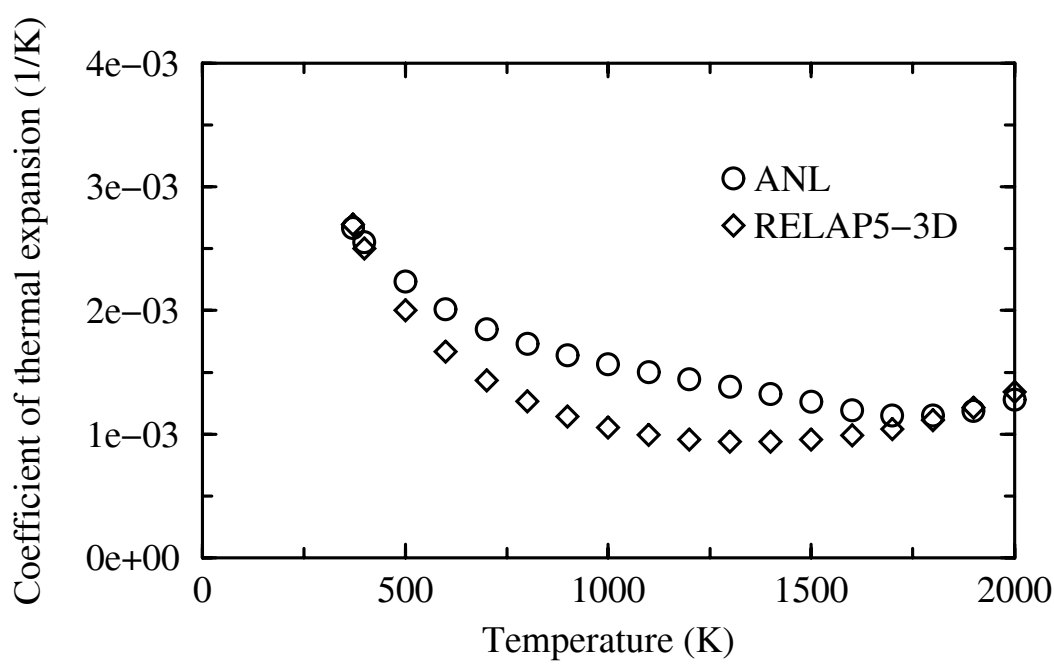

Figure 14. Coefficient of thermal expansion of saturated vapor. 


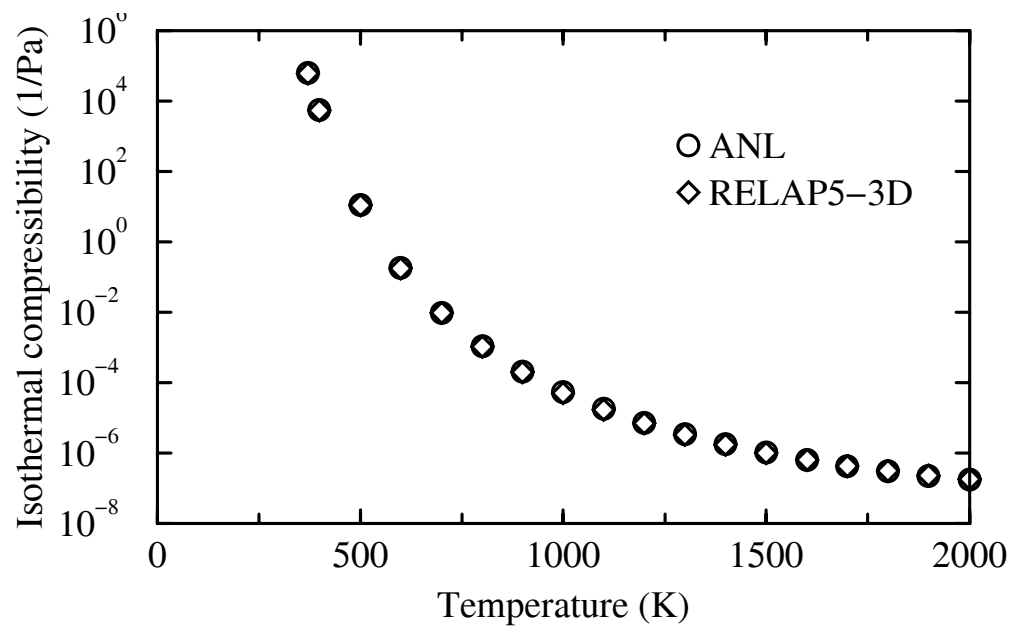

Figure 15. Coefficient of isothermal compressibility of saturated vapor.

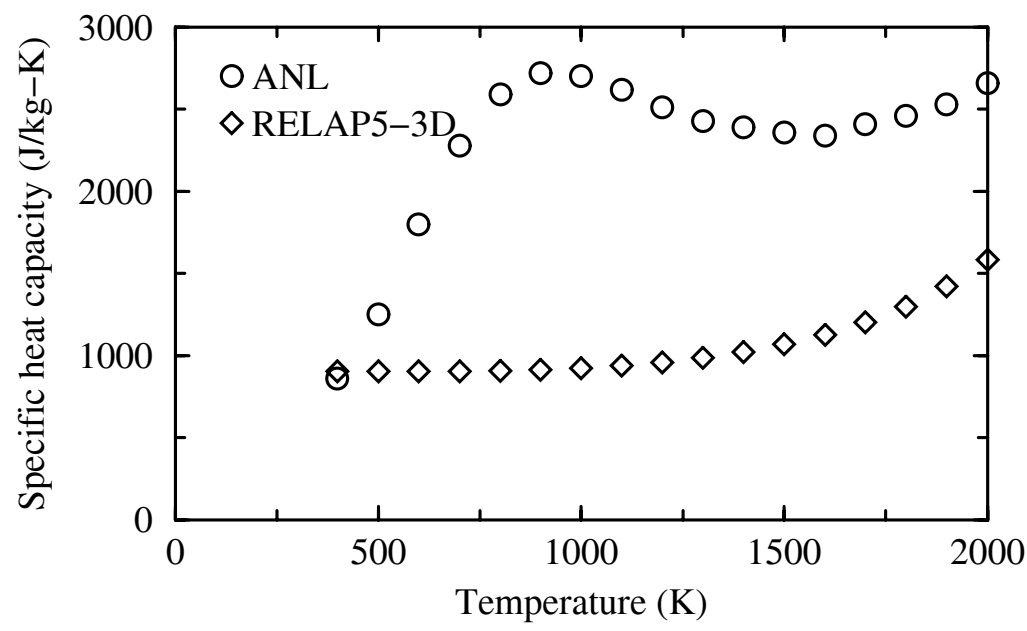

Figure 16. Specific heat capacity at constant pressure of saturated vapor.

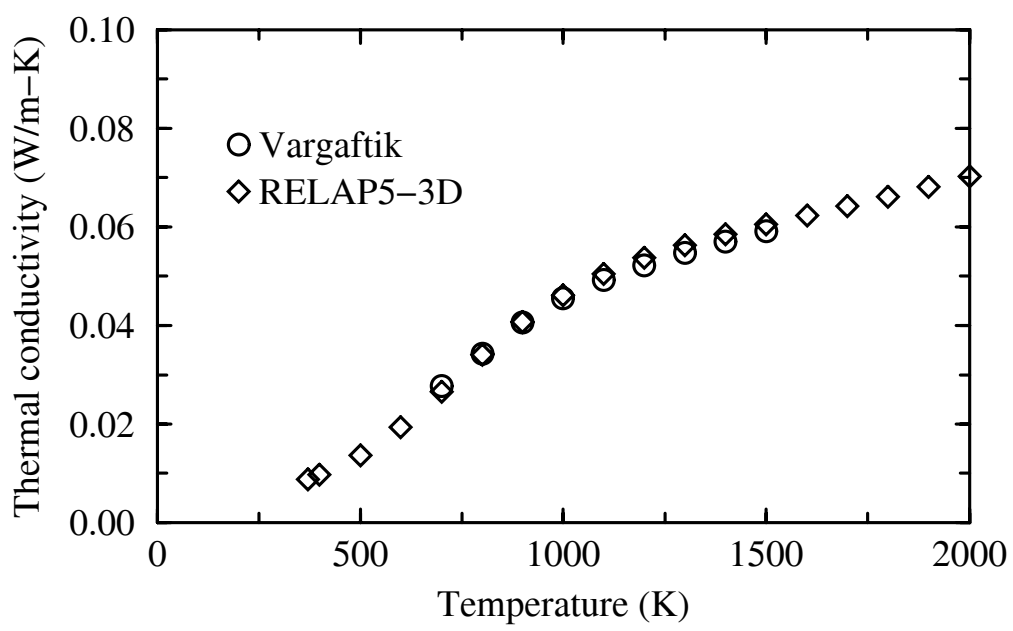

Figure 17. Thermal conductivity of saturated vapor. 


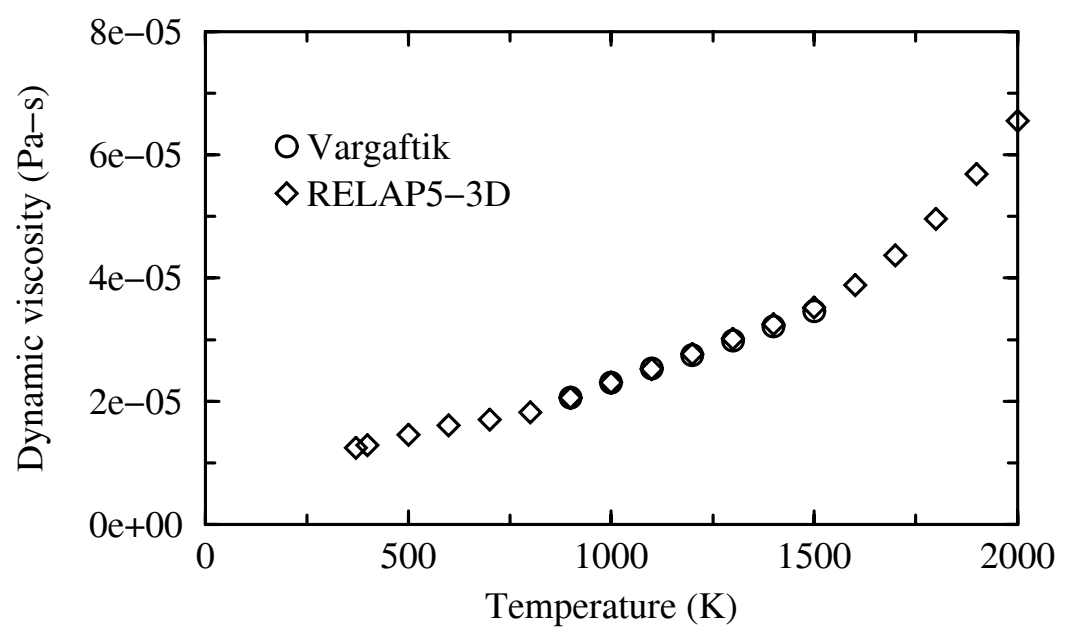

Figure 18. Dynamic viscosity of saturated vapor.

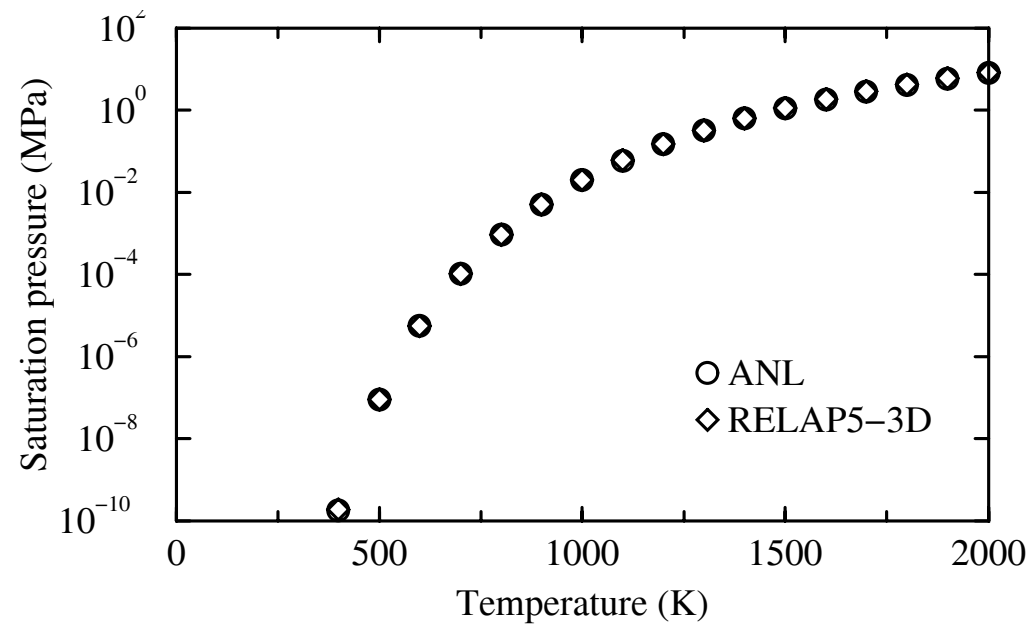

Figure 19. Saturation pressure versus temperature.

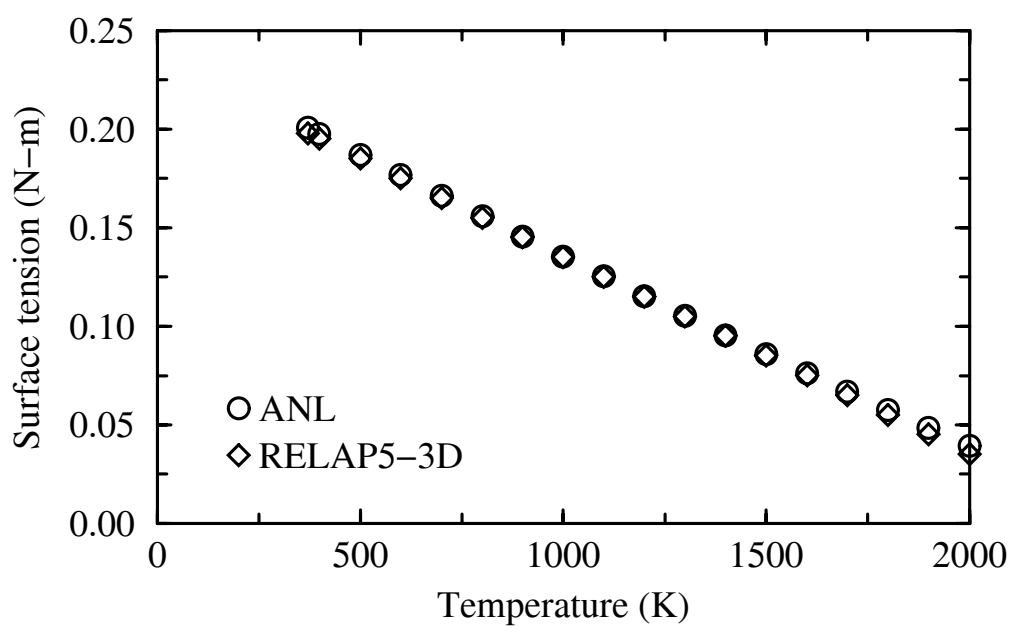

Figure 20. Surface tension versus temperature. 
The results presented in Table 1 and Figures 5 through 20 show that the fluid properties calculated by RELAP5-3D are generally in reasonable to excellent agreement with the values reported by ANL. For example, the liquid specific volume shown in Figure 5 was judged to be in reasonable agreement with the values reported by ANL. The calculated trends were similar to those reported by ANL. Although the deviation between the RELAP5-3D and ANL values considerably exceeded the estimated uncertainty at $700 \mathrm{~K}$, which is near the expected average fluid temperature of the ABTR during normal operation, the absolute value of the deviation was only a few percent, which was judged to be acceptable agreement for a system analysis tool. The relative deviation between the ANL and RELAP5-3D values increased with temperature, but the estimated relative uncertainty also increased. In fact, the calculated specific volume was within the estimated uncertainty for temperatures above $1600 \mathrm{~K}$. The deviations in the coefficients of thermal expansion and isothermal compressibility, which are normalized derivatives of the specific volume with respect to the temperature and pressure, were larger than those of the specific volume but were within or nearly within the uncertainty bands.

The calculated specific internal energy of the liquid was judged to be in reasonable agreement with the values reported by ANL. However, the specific heat capacity at constant pressure was judged to be in minimal agreement. Figure 9 shows that values predicted by RELAP5-3D were lower than the values reported by ANL below $1100 \mathrm{~K}$ and exceeded the reported values above $1500 \mathrm{~K}$. The temperature at which the minimum specific heat capacity occurred was about $600 \mathrm{~K}$ with RELAP5-3D, which was about $400 \mathrm{~K}$ lower than the temperature at which ANL reported that the minimum occurred. At the expected normal operating temperature of $700 \mathrm{~K}$, the value predicted by RELAP5-3D was $8 \%$ lower than the value reported by ANL versus an estimated uncertainty of $2 \%$. This deviation should cause an $8 \%$ error in the code's calculation of temperature rise across the core power during normal operation. Note that the specific heat capacity values reported by ANL are consistent with the values reported by Vargaftik (1975). It is recommended that the adjustable constants in the soft-sphere model be varied in an attempt to better fit the specific heat values reported by ANL below $1100 \mathrm{~K}$. Larger errors above $1100 \mathrm{~K}$ could be tolerated because the ABTR is not expected to achieve temperatures that high except during severe accidents.

The calculated specific heat capacity at constant pressure of the saturated vapor, see Figure 16, was judged to be in insufficient agreement with the values reported by ANL. The ANL values reached a maximum near $900 \mathrm{~K}$ and a minimum near $1600 \mathrm{~K}$, whereas the values calculated by RELAP5-3D increased monotonically with temperature. The calculated values were also generally far outside of the estimated uncertainty band. However, the impact of the large deviations between the calculated and reported values is not expected to be significant in the analysis of the ABTR because the liquid phase is of primary interest.

Fink and Leibowitz (1995) did not recommend values or uncertainties for the thermal conductivity and dynamic viscosity of saturated sodium vapor. The correlations used by RELAP5-3D to calculate these properties were based on fits to the values reported by Vargaftik (1975). Figures 17 and 18 show that the correlations used by RELAP5-3D fit the values reported by Vargaftik well. The calculated values below $700 \mathrm{~K}$ for thermal conductivity and $900 \mathrm{~K}$ for dynamic viscosity and above $1500 \mathrm{~K}$ for both properties are extrapolations.

\section{CONCLUSIONS}

Peak temperature at the inside surface of the cladding was the primary figure of merit for the evaluation of safety in the EBR-II. Consequently, peak cladding temperature is also expected to be the primary figure of merit for the ABTR. 
The station blackout will be the limiting event for the design of the shutdown cooling system in the ABTR. Transients initiated by loss of forced circulation of the primary coolant and loss of secondary heat sink will also be important. The ABTR will likely have to demonstrate that it is as least as safe as previous fast reactors, such as EBR-II. Consequently, the performance of the reactor during transients without reactor scram will also have to be considered.

The important phenomena that affect the peak cladding temperature during transients include the frictional characteristics of the subassembly, the coastdown characteristics of the primary coolant pumps, mixing and thermal stratification within the reactor tank, the heat transfer characteristics from the fuel rod, and the performance of the secondary coolant system, the power conversion unit, and the passive decay heat removal system. Reactivity feedback effects due to thermal expansion were identified as important during transients without scram. Decay heat was identified as important during transients with scram.

The code's models for the coastdown of the primary coolant pumps, the performance of the secondary coolant system, the power conversion unit, and the passive decay heat removal system were all judged to be adequate for simulating the ABTR. Although the code does not have models for thermal stratification in the reactor tank, the combination of bounding sensitivity calculations and the code's capability to couple with Fluent, a CFD code, was judged to provide an adequate analytical capability.

The applicability evaluation indicated that two models needed to be added to the code to simulate the ABTR. An electromagnetic pump model needs to be added to the code. The code also needs to model axial conduction in the fluid.

Several improvements to various code models were identified to better represent the ABTR. These improvements, which require relatively minor changes to the coding, included: (1) modifying the transition region between laminar and turbulent flow to represent the wire-wrapped rod bundle, (2) allowing negative values of the B constant in the user-input Reynolds-number dependent form loss coefficient to better represent the losses associated with an orifice, (3) changing the constant in the default heat transfer correlation for liquid metals from 5 to 7 to represent a constant heat flux boundary condition rather than a constant wall temperature boundary condition, and (4) changing the bundle heat transfer correlation for liquid metals from that of Westinghouse to that of Borishanskii et al.

Several long-term changes were also identified that would result in an improved analytical capability, but are not required for immediate analyses. These recommended changes, which are somewhat dependent on the yet-to-be-determined design of the ABTR included: (1) implement mechanical models to calculate the effects of thermal expansion on the geometry of various core components for a more mechanistic calculation of reactivity feedback, (2) implement an improved model to account for the decay heat associated with the actinides that will be burned in the ABTR, and (3) implement a more general form of the equation defining the form loss coefficient as a function of Reynolds number to better represent the orifice loss characteristics over a wider range of Reynolds number.

The sodium fluid properties in RELAP5-3D were generally in reasonable or excellent agreement with values from other sources of data. However, the specific heat capacities of the liquid and vapor phases were judged to be in minimal and insufficient agreement, respectively. The discrepancy in the vapor specific heat capacity was not judged to be significant for analysis of the ABTR. However, the discrepancy for the liquid phase was judged to be significant. For example, the liquid specific heat capacity calculated by RELAP5-3D was estimated to be about $8 \%$ too low for the operating conditions expected in the ABTR. It is recommended that the adjustable constants in the soft sphere model be modified to better match ANL values for temperatures below $1100 \mathrm{~K}$. 


\section{REFERENCES}

Berkan, R. C., B. R. Upadhyaya, and R. A. Kisner, 1990, Low-Order Dynamic Modeling of the Experimental Breeder Reactor II, ORNL/TM-11161, July.

Bird, R. B., W. E. Stewart, and E. N. Lightfoot, 1960, Transport Phenomena, John Wiley \& Sons, Inc., New York.

Boardman, C. E., A. E. Dubberly, D. G. Carroll, M. Hui, A. W. Fanning, and W. Kwant, 2000, “A Description of the S-PRISM Plant," ICONE-8168, Proceedings of ICONE-8, Baltimore, Maryland, April $2-6$.

Borishanskii, V. M., M. A. Gotorsky, and E. V. Firsova, 1969, "Heat Transfer to Liquid Metal Flowing Longitudinally in Wetted Bundles of Rods," Atomic Energy, 27:549.

Cheng, S. K. and N. E. Todreas, 1986, "Hydrodynamic Models and Correlations for Bare and WireWrapped Hexagonal Rod Bundles - Bundle Friction Factors, Subchannel Friction Factors and Mixing Parameters," Nuclear Engineering and Design, 92 (1986), pp. 227 - 251.

Colebrook, C. F., 1939 "Turbulent Flow in Pipes with Particular Reference to the Transition Region Between Smooth and Rough Pipe Laws," Journal of Institute of Civil Engineers, 11, pp. 133-156.

Croff, A. G., 1980, A User's Manual for the ORIGEN2 Computer Code, ORNL/TM-7175.

Davis, C. B. and G. L. Hawkes, 2006, "Thermal-Hydraulic Analyses of the LS-VHTR," Proceedings of ICAPP '06, Reno, NV, 6208, June 4-8.

Dunn, F. E. et al., 1985, “The SASSYS-1 LMFBR Systems Analysis Code," Proceedings of the International Meeting on Fast Reactor Safety, Knoxville, Tennessee.

Feldman, E. E., D. Mohr, L. K. Chang, H. P. Planchon, E. M. Dean, and P. R. Betten, 1987, "EBR-II Unprotected Loss-of-Heat-Sink Predictions and Preliminary Test Results," Nuclear Engineering and Design, 101, pp. 57-66.

Fink, J. K. and L. Leibowitz, 1995, Thermodynamic and Transport Properties of Sodium Liquid and Vapor, ANL/RE-95/2, January.

Golden, G. H., H. P. Planchon, J. I. Sackett, and R. M. Singer, 1987, "Evolution of Thermal-Hydraulics Testing in EBR-II,", Nuclear Engineering and Design, 101, pp. 3-12.

Hejzlar, P. and C. B. Davis, 2004, "Performance of the Lead-Alloy-Cooled Reactor Concept Balanced for Actinide Burning and Electricity Production," Nuclear Technology, 147 (3), pp. 344 - 367.

Idelchik, I. E., 1994, Handbook of Hydraulic Resistance, Third Edition, CRC Press, Boca Raton.

Kays, W. M. and M. E. Crawford, 1980, Convective Heat and Mass Transfer, Second Edition, McGrawHill Book Company, New York.

Lehto, W. K., R. M. Fryer, E. M. Dean, J. F. Koenig, L. K. Chang, D. Mohr, and E. E. Feldman, 1987, "Safety Analysis for the Loss-of-Flow and Loss-of-Heat Sink Without Scram Tests in EBR-II," Nuclear Engineering and Design, 101, pp. 35-44. 
Liang, T. K. S., F. K. Ko, C. Y. Yang, and Y. S. Tsai, 2004, "Feedwater Blowdown Analysis for ABWR Containment Design," 2004 RELAP5 International Users Seminar, Sun Valley, Idaho, August 25-27.

Mohr, D., L. K. Chang, E. E. Feldman, P. R. Betten, and H. P. Planchon, 1987, "Loss-of-Primary-Flow Without-Scram Tests: Pretest Predictions and Preliminary Results," Nuclear Engineering and Design, 101, pp. 45-56.

RELAP5-3D Development Team, 2005, RELAP5-3D Code Manual Volume 1: Code Structure, System Models and Solution Methods, INEEL-EXT-98-00834, Revision 2.3, April.

Schultz, R. R., W. L. Weaver, R. W. Johnson, D. Schowalter, and N. Basu, 2005, "Evaluating Fluid Behavior in Advanced Reactor Systems Using Coupled Computational Fluid Dynamics and Systems Analysis Tools," Proceedings of ICONE 13, ICONE 13-50723, Beijing China, May.

Todreas, N. E. and M. S. Kazimi, 1990, Nuclear Systems I Thermal Hydraulic Fundamentals, Hemisphere Publishing Corporation, New York.

Turinsky, P. J. et al., 1994, NESTLE: A Few-Group Neutron Diffusion Equation Solver Utilizing the Nodal Expansion Method for Eigenvalue, Adjoint, Fixed-Source Steady State and Transient Problems, EGG-NRE-11406, June.

Vargaftik, N. B., 1975, Tables on the Thermophysical Properties of Liquids and Gases, Hemisphere Publishing Corporation, Washington.

Young, D. A., 1977, A Soft Sphere Model for Liquid Metals, Lawrence Livermore Laboratory, UCRL52352, November 8 .

Zigrang, D. J. and N. D. Sylvester, 1985, "A Review of Explicit Friction Factor Equations," Transactions of ASME, Journal of Energy Resources Technology, 107, pp. 280-283. 